Article

\title{
Sustainable Management of Underwater Cultural Heritage: The Route from Discovery to Engagement-Open Issues in the Mediterranean
}

\author{
Vasilike Argyropoulos ${ }^{1, *,+}$ (i) and Anastasia Stratigea ${ }^{2,+}+($ ) \\ 1 University of West Attica, Department of Conservation of Antiquities and Works of Art, Ag. Spyridonos, \\ 12243 Aegaleo, Greece \\ 2 Department of Geography and Regional Planning, School of Rural and Surveying Engineering, \\ National Technical University of Athens, 15780 Athens, Greece; stratige@central.ntua.gr \\ * Correspondence: bessie@uniwa.gr; Tel.: +30-210-538-5459 \\ + These authors contributed equally to this work.
}

Received: 28 March 2019; Accepted: 30 May 2019; Published: 3 June 2019

\begin{abstract}
Fatal events taking place in World War (WW) I and II have left behind important historical evidence as an underwater cultural heritage (UCH) (e.g., shipwrecks, submerged aircraft, war artifacts), lying in peace at the bottom of, among others, the Mediterranean Sea. The article aims at exploring the challenges for $\mathrm{UCH}$ protection/preservation and sustainable exploitation with emphasis on this sea. UCH is so far dealt with in a "silo" approach by marine archaeologists or heritage professionals, who often ignore its potential for serving local sustainable development goals. The paper elaborates on the value, but also the complexity, multi- and inter-disciplinary as well as multi-actors' nature of $\mathrm{UCH}$ management and sustainable exploitation, perceiving these as a "wicked" planning problem. It attempts to illuminate various important dimensions of this problem, such as its glocal (global/local) context; the conflicting and, in certain cases, inconsistent $\mathrm{UCH}$ legal protection framework, touching upon a variety of spatial scales; the contemporary policy frameworks favoring UCH management; etc. Exploration of these dimensions reveals open issues or gaps that need to be filled, and sets the ground for a more holistic and integrated $\mathrm{UCH}$ research and management approach for building up the yet largely untold, Mediterranean WW I and II UCH narrative; and shifting this area from a sea graveyard to a place of memory and cultural enrichment.
\end{abstract}

Keywords: UCH governance; Mediterranean region; legislative and policy framework; local development; preservation; public engagement; integrated and participatory planning

\section{Introduction}

"The remembrance of the past through historic sites and artifacts can significantly contribute to peace and reconciliation in the twenty-first century". The outstanding importance of cultural heritage $(\mathrm{CH})$ in the future of society as a whole is distinctively illustrated in the preceding short but quite comprehensive statement, articulated by Alfredo Pérez de Armiñán [1] (p. 5). Speaking of $\mathrm{CH}$, it is often said that there is more history underwater than in all the museums of the world combined [2], forming a large part of our shared $\mathrm{CH}$. Indeed, various traces of this $\mathrm{CH}$ can be identified at the sea bottom which, according to UNESCO (2001) [3] (Article 1), incorporate submerged sites, structures, buildings or works and remnants of human activity; and submerged ships, aircraft and other objects or parts of them and their contents, all of which are placed in an archaeological or natural environment. Among these remnants are encountered underwater metal wrecks, which represent tangible traces of naval and near-shore conflicts of WW I and II, and transform in time to fossilized fragments of history and marine micro-ecosystems. As time passes, and there are no longer eyewitnesses to remind us of the 
dramatic events of the WW I and II historical period, there seems to be a widely recognized need for these tangible traces to be preserved and sustainably exploited as well as bridged to the traditions and recorded personal testimonies. Such a preservation and sustainable exploitation will serve the 'big image', i.e., the integrity of our European identity of the past; but will also streamline sustainable, resilient and inclusive heritage-led developmental objectives of the localities, in the surroundings of which this heritage has been discovered [4-9].

Today, there is a heightened recognition of the importance of WW I and II UCH at various policy making levels (e.g., UNESCO, flag nations and coastal states, Europe) as a significant part of our cultural heritage that bears a variety of meanings associated with political, social, economic, cultural, environmental, technical and technological viewpoints [5,6].

Speaking of the European continent, its coastal and maritime regions have often become main WW I and II theaters due to their strategic geographical position, economic importance and role in protecting national borders and sovereignty. In such a context, these regions constitute important scenes of WW I and II UCH evidence. Interpreting, preserving, and sustainably managing this UCH across such regions is crucial for keeping alive memory and honoring past historical events and human losses; protecting the integrity of the European identity; educating future generations in peace and avoidance of past failures [10]; and shifting tragedies/heroic acts into value for regions. However, different European coastal and maritime regions are confronted with diversified challenges, e.g., urbanization, climate change impacts, pollution of marine environment [11] that imply the necessity for a more region-specific WW I and II UCH preservation handling.

The focus of this article is on the Mediterranean Region. This region, being at the crossroad of three continents, has played a major role during WW I and particularly WW II, which is largely unknown to the wider public [12]. It actually served as a pivotal war operations' scene, "The Mediterranean Theater of Operations" [13], with important battlegrounds so as to dominate the Mediterranean by controlling its coasts and islands through naval bases and facilities. Moreover, the Mediterranean was perceived as an important sea route, i.e., a busy traffic area for the transportation of essential raw materials during the wars (e.g., cargos in Alexandria during WW I) and transportation of troops from the different nations (e.g., Marseille, the main port in the Mediterranean during WW I) [14].

As a result, the Mediterranean region has some of the most important WW I and especially WW II UCH, acting as a witness of important interconnected naval, land, and air war campaigns. WW I and II UCH evidence in the Mediterranean incorporates many sunken wrecks and their remains, as well as chronicles of these times, depicted in museums, memorials, shelters, harbors, quays, etc. This UCH serves as memorials or graves, commemorating some of the most well-known maritime disasters, such as HMHS Britannic [15], S/S Oria [16]; famous near shore battles (naval and/or air) such as 'The Battle of Leros' [17]; and landings such as 'Operation Dragoon' [18]. Still others are unique examples of a vessel type, or hold iconic status for a nation, or are associated with naval tragedies involving loss of life, e.g., Jewish refugees on the Athina/Rafiah [19].

Some first important remarks as to the large number of WW I and especially WW II sunken vessels, lying at the bottom of the Mediterranean Sea, are as follows:

- The narrative of many of the Mediterranean WW I and especially WW II battlefields or naval tragedies is not well known today by the general public.

- The exact number and location of sunken WW I and II vessels in the Mediterranean is not yet fully known.

- These vessels, as evidence of WW I and II historical events, are in many cases already lost. For example, many of WW I and especially WW II UCH were or still are salvaged for scrap metal $[16,20]$. An example of this is S/S Oria, which sunk off the island of Patroklos near Attica Region [16]. Those that usually remain untouched are sunken vessels in deep waters or submerged aircraft.

- Archaeological research in the Mediterranean is somehow lagging behind with respect to UCH and is mainly focused on terrestrial and coastal $\mathrm{CH}$, given the large number of UNESCO World 
Heritage Sites located in this area that are mostly found at a very short distance from the coastline (e.g., in Greece, Portugal, Italy, Malta, Tunisia, Egypt, Cyprus).

- Despite the historical value of a great number of Mediterranean sites and the abundance of their remnants (see Figure 1 below), a lack of a systematic effort to map and document these sites as WW I and II battlefield tourism destinations is noticed, which could produce value for their local communities. Such efforts though have been carried out by other relevant sites in northern Europe or elsewhere in the World (see [21]). Some well-known battlefield tourism sites are for example: Normandy France, where the D-Day Landing beaches are highly popular destinations for battlefield tourism, with the 70th anniversary in 2014 drawing some of the greatest number in visitors [22]; Solomon Islands, Oceania, shifting geography of war to layers of memory in the form of plaques, monuments, and memorials as significant reminders of the events that once made the Solomon Islands the center of world attention [21]; Chuuk state, Federated States of Micronesia, being Japan's heavily fortified main base in the South Pacific Theater and a currently worldwide scuba diving paradise due to its numerous, virtually intact sunken ships, the "Ghost Fleet of Truk Lagoon" [23].

- Full protection of UCH has not been achieved, as UNESCO Convention (not signed by all relevant countries) protects only WW I UCH (older than 100 years), while leaving aside WW II UCH (submerged less than 100 years).

Further to the above remarks, the fact that the Mediterranean is nowadays perceived as one of the most highly-rated hot spot regions in the world in many respects (climate change, marine pollution, urbanization, aggregate extraction etc.) [11], renders preservation and sustainable management of WW I and II UCH in this area a challenging field for a range of disciplines and policy makers [1,24]. The authors believe that this is justified from both a preservation and sustainable exploitation point of view.

From a preservation point of view, it seems that WW I and especially WW II sunken vessels in the Mediterranean are endangered, while still insufficiently protected, explored, researched and featured. Key concerns in this respect emanate from the:

- High vulnerability, as opposed to other types of $\mathrm{UCH}$, due to its construction materials and the high salinity of the Mediterranean Sea, expected to further deteriorate due to climate change impacts;

- Diverse interests/stakes involved and related inherent values ranging from local to global level, as well as the lack of common understanding and governance of $\mathrm{UCH}$;

- Lack of adequate knowledge with regard to the UCH position, condition, safety, impact on the marine environment, etc.;

- Impacts related to anthropogenic factors (e.g., transportation, tourism, fishing), placing WW I and II UCH at risk.

From a sustainable exploitation point of view, WW I and II UCH are:

- Rather fragmentarily exploited (e.g., diving activities), largely ignoring its social, ethical, symbolic, historical, cultural and environmental values;

- Lacking an integrated management approach of tangible and intangible UCH and related terrestrial $\mathrm{CH}$ aspects (wherever relevant) for understanding the full narrative behind them and transmitting lessons learnt towards the European community;

- Underestimated with regards to its power for generating growth by shifting, under certain preconditions, war scenes/remnants to economic opportunity, e.g., coastal/maritime cultural tourism, Cultural Creative Industry (CCI) productions related to WW I and II to name a few.

The inherent value attached to this heritage and the high risk of its loss, if preservation is not undertaken soon, is the motivation behind this article. More specifically, the goal of the present work is to outline a range of issues, still open for research, discussion and policy making, which need to 
be properly handled in the Mediterranean for long term preservation and sustainable WW I and II UCH management objectives to be attained. In fulfilling this goal, this article is structured as follows: First, the Mediterranean WW I and II UCH historical context is addressed; this is followed by current considerations with regards to its protection and preservation as well as spatial considerations of this UCH within the framework of the blue growth strategy and Marine Spatial Planning (MSP); elaboration of open issues for research, discussion and policy concern are then sketched; while finally a summary of concluding statements is provided.

\section{WW I and II Underwater Cultural Heritage in the Mediterranean}

WW I and II UCH are mostly the result of naval and/or air battlefield incidents in strategic locations in the Mediterranean that were controlled as important transport routes during these wars; while there are also many examples of UCH from these wars that were the outcome of accidents or explosion from mines. The number of wrecks at various locations varies, while the same holds for their type (warships, aircraft, submarines, cargo, trawlers, landing crafts, etc.). Many of them are also acting as memorials to human losses since they contain human remains of different nationalities (American, Australian, British, French, Greek, Italian, and Japanese, to name a few). Such remains raise ethical issues with regard to their public access. In certain occasions, $\mathrm{UCH}$ marine sites are associated with important terrestrial cultural assets, established on the coastal neighboring part, such as museums, memorials, or remnants of WW I and II military infrastructures, which represent an important counterpart to the sites' narrative, e.g., the island of Leros, Greece as an example of WW II battleground [7].

The following sections present the historical context of WW I and II UCH, coupled with some significant WW I and II UCH marine sites and related war operations.

\subsection{WW I UCH Context}

In the Mediterranean region there are few, but still quite important, WW I UCH marine sites, closely related to famous naval battles, such as the Battles of Gallipoli and Otranto Barrage [25]. The region was the strong-hold of the French and British fleets, including Italy, when it entered the war on the Allied side [26], playing an important role in countering Germany's U-boat campaign in the Mediterranean (1914-1918) by patrolling its seas and escorting ships through its trade routes [25]. There has been well-documented exploration and diving on the most famous wrecks from this era. As examples can be mentioned, the SS Burdigala [16] and the HMHS Britannic off the coast of Kea [16], Greece; the Baron Gautsch and SMS Szent István [27], Croatia; the Danton, off the coast of Sardinia [28], just to name a few.

Significant marine sites also exist in Gallipoli, Turkey, where a number of wrecks are encountered as a result of the Gallipoli campaign [25]. Between 25 April 1915 and 9 January 1916, a joint British and French operation was mounted to capture the Ottoman capital of Constantinople (now Istanbul) by attempting a naval breakthrough in the Dardanelles straits to secure a sea route to Russia [25]. After this failed attempt, a land campaign on Turkey's Gallipoli peninsula took place using Australian and New Zealand troops.

Remains of this campaign, incorporating an extensive range of sunken ships, guns, trenches, forts, bastions, and a myriad of other war-related artifacts, together with Turkish, Australian, New Zealand, English, and French war graves, are today sheltered in the Gallipoli Peninsula National Historical Park. Most of these are registered as historical sites and objects [29]. To date, some reports state that there are several hundreds of wrecks discovered from this famous battle in the coastal waters between Anzac Cove and Suvla Bay [25]. The Gallipoli Park is a protected area, covering over 330 square kilometers at the southern end of the Gallipoli Peninsula on the European side of the Dardanelles; and is one of the best known diving sites for WW I wrecks in the Mediterranean. Shallow water diving tours are organized to these wrecks [25,30]. Since 1997, there have been many efforts to survey and document these wrecks either by film or using 3D multi-beam sonar imaging [30,31]. It should be however noted that to date this national park does not have a sustainable management plan for effectively handling its 
$\mathrm{UCH}$ [29]. Recently, there have been efforts to research and preserve in-situ some of the sunken vessels by a joint Australian-Turkish team under the auspices of the project known as 'Beneath Gallipoli' [32].

\subsection{WW II UCH Context}

As WW II was the most geographically widespread military conflict the world has ever seen and a "watershed event in history" [21] (p. 125), there is a vast number of WW II military UCH at the bottom of the world's oceans. The figures reported are as follows [33]: 1875 US vessels, 766 German submarines, 2775 allied ships sunk by German U-boats, and 3032 Japanese vessels sunk by the Allies. A large share of this UCH remains in the Mediterranean waters since, in contrast to WW I, the WW II period (1939-1945) was marked by the extended naval warfare and military operations that took place in this area, resulting in a large number of sites and an abundant number of remnants of these operations, lying at the bottom of the Mediterranean Sea [34,35]. Indeed, thousands of UCH marine sites that played a role as war scenes are scattered around the Mediterranean shores in Croatia, southern France, Greece, Italy, Malta, including North Africa (Figure 1), witnessing the largest actions of naval warfare aside from the 'Pacific Theater' [12].

Historically speaking, the 'Battle of the Mediterranean' (June 1940-May 1945) was the campaign fought between the Italian Royal Navy supported by the Axis naval and air forces, and the British Royal Navy supported by Allied naval forces [36]. In parallel, the Americans with the support of the Allies began a Mediterranean theater of operations, where land and seas were invaded or defended on an axis starting from one sea, crossing a large land mass, and ending at another sea. The main campaigns were in North Africa and Italy, and later in the Eastern Mediterranean (Dodecanese Campaign), including operations to free the French Mediterranean coast ('Operation Dragoon') [18]. Some military historians have argued that the 'Mediterranean Theater' in WW II played a significant role in the Allied victory in Europe, by providing an alternative battlefield route to the Western Allies, so as to avoid the commitment to a premature cross-channel invasion from England to France in 1943 [12].

Some Mediterranean battlefields are seen as Allied failures against the Axis forces. Such a failure was the Dodecanese Campaign, led by the British Allied forces to take or hold control of the Italian-held Dodecanese islands in the Aegean Sea from the Germans, after Italy's surrender on 8 September 1943. The Americans did not support Winston Churchill's decision to take control of the Eastern Mediterranean, since they believed it would divert attention from the Italian Campaign [12]. The British forces from 10 to 17 September 1943 took hold of the islands running between Castellorizo in the south and Samos in the north, with the exception of Rhodes, which already had substantial German forces [37] (p.113). Thousands of British troops landed on the islands of Kos, Leros, and Samos to help the Italian troops, but the Germans mounted a counteroffensive to take over the islands through 'Operation Leopard' [37].

The naval and air battles that took place on the islands of Leros and Kos were the last big German victories of the war, and resulted in the German occupation of Dodecanese islands' complex as a whole by the end of November 1943 until the end of the war. Chant (2013) [37] describes the losses of these battles as 4800 British and 4000 Germans causalities; and sunken wrecks for the British 115 aircraft losses, six sunk destroyers, two sunk submarines, ten coastal/minesweepers. The Royal Hellenic Navy (RHN) also had casualties in these battles and lost ships, such as the famous RHNS Vasilissa Olga, which played its role up to then in campaigns all over the Mediterranean [16]. This ship carried pride and emotion for the RHN, since it was chosen to participate with the Allied fleet, when the Italians surrendered in Sardinia [16]. After this campaign, many Italians were taken as war prisoners and were transferred to mainland Greece in ships, some of which were sunk either by accident or intentionally by Allied forces. The most deadly was the German controlled S/S Oria, which sunk on 12 February 1944, with 4000 Italian prisoner casualties [16]. Many of the vessels, sunk during the Dodecanese Campaign, have still not been located today. 

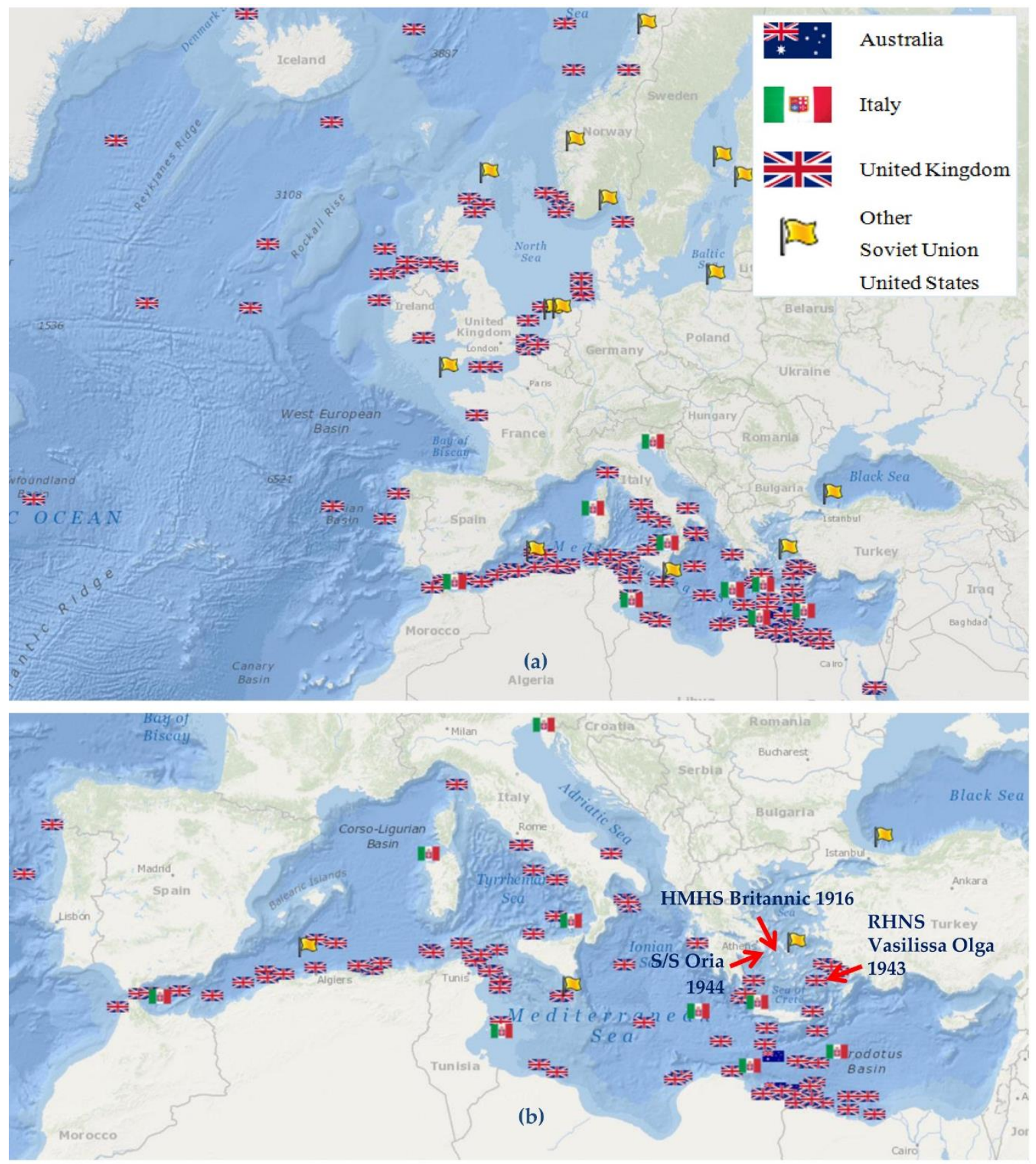

Figure 1. World war (WW) II shipwrecks: (a) In Europe and (b) in the Mediterranean (credit: GEBCO, IHO-IOC GEBCO, NGS, DeLorme, Esri with data for shipwreck locations Wikipedia) [38].

An important example of a WW II battlefield is also the island of Leros, in which 'The Battle of Leros' (November 1943) has left behind important evidence of WW II UCH (Figure 2), lying in the bays, ports or surrounding coastline of this small island, the second most bombed island after Crete in Greece during WW II. The island is considered a natural fortress due to its topography. Its strategic position in the Eastern Mediterranean, with large harbors and the port of Lakki with very deep waters, has rendered it an important naval base during both WW I and II; while it has also important terrestrial WW II cultural assets, such as remnants of gun emplacements, army barracks etc. (Figure 2) [7]. Some research on the WW II UCH carried out so far on the island of Leros has revealed WW II sites of historical but also of natural value [39]. WW II UCH research on Leros has documented 
two barges in the bays of the island, an antisubmarine ship, landing crafts, three submerged aircraft, and anti-submarine nets, as well as remnants of the famous flagship Vasilissa Olga.
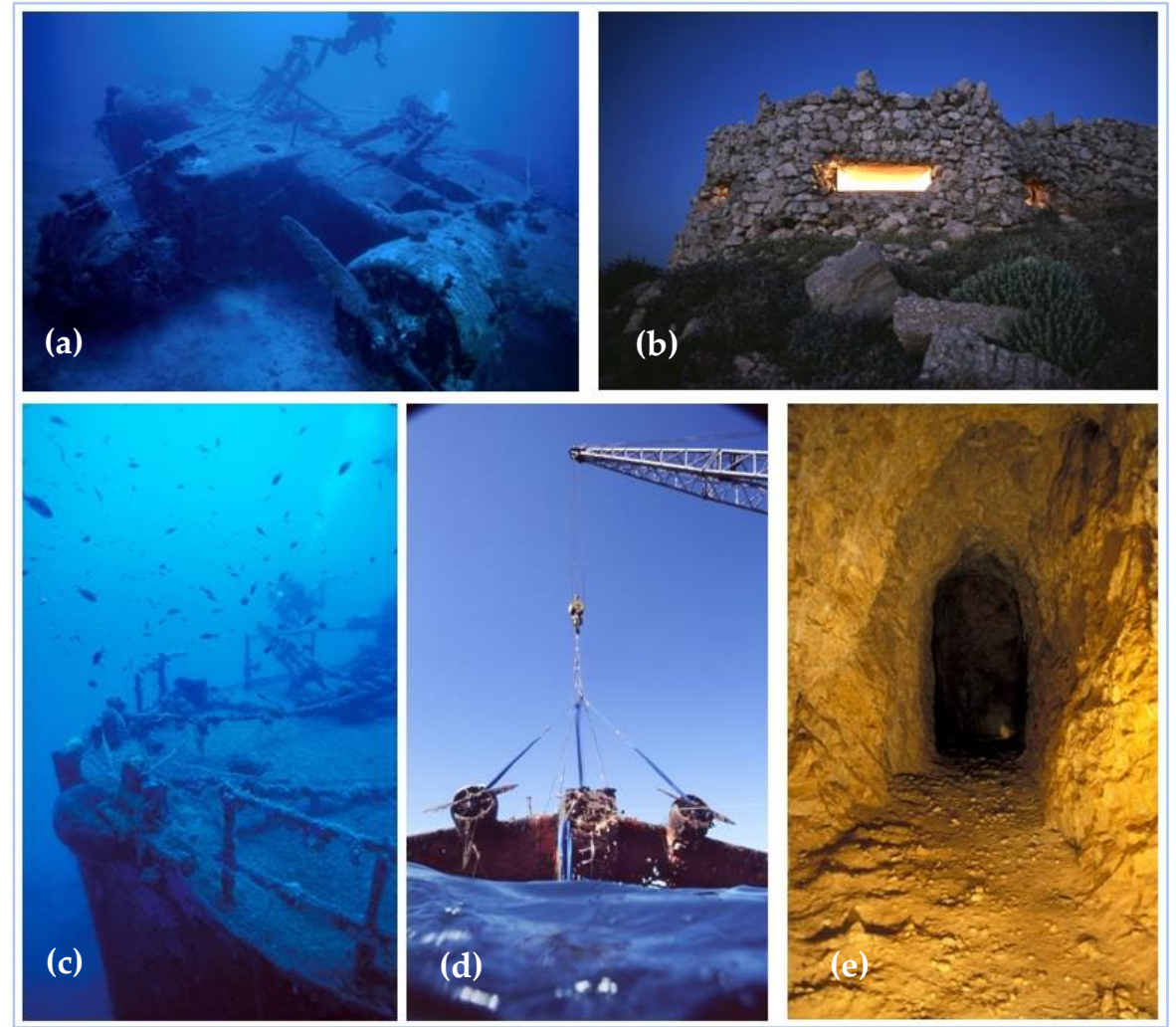

Figure 2. Land and maritime WW II remnants in Leros Island, Greece: (a) A German Junkers-52 found at a depth of $42 \mathrm{~m}$ at the bottom of Alida Bay, two nautical miles north-east of Leros; (b) the observation post/battery of the Farinata Battery on Mount Markelos; (c) a barge found at the bottom of Partheni Bay sunk by a torpedo fired from a German aircraft; (d) the same German Junkers-52 shown in the top left image, lifted in 2003 now located in the Hellenic Air Force Museum in Tatoi, Athens; (e) inside the Lepida shelter-almost the whole of Leros is honeycombed with such large and small shelters. Source: [17].

\section{Current Considerations for Protection and Preservation of WW I and II UCH}

This section explores the current state of the issue of WW I and II UCH protection and preservation by providing a brief summary of the current legislative framework. It also elaborates on 'glocal' challenges but also opportunities ahead that need to be addressed in order for barriers to WW I and especially II protection/preservation in the Mediterranean be removed. Finally, it briefly presents successful examples of UCH sustainable management practices, grounded on the Pacific WW I and II experience.

\subsection{Current Legislative Protection Framework}

The core legislative framework for the protection of military wrecks as sovereign immunity of the flag state and/or their designation as a cultural resource for both the flag and coastal states, depending on the location of $\mathrm{UCH}$, is provided by the:

- 1982 United Nations Convention on the Law of the Sea (UNCLOS) [40]: Defines the rights and responsibilities of nations with respect to their use of the world's oceans. Its numerous provisions delineate sea areas or maritime zones as well as the rights and uses of these zones by coastal states and foreign vessels within these zones. The convention provides definitions of a warship as well 
as the sovereign immunity of warships on the high seas, and it is used as a reference point for the UNESCO 2001 Convention (see below). It also sets out the rights and jurisdictions of states in the sea, which indirectly affects the potential for implementing states' $\mathrm{UCH}$ protection policies, in alignment with each single state's legislative context.

- 1992 European Convention on the Protection of the Archaeological Heritage (Valetta or Malta Convention) [41]: Aims to protect archaeological heritage as a source of European common memory and a resource for historical and scientific study. Particularly, it focuses on: the maximum retention of items of archaeological value in the seabed (in-situ), the obligation to report archaeological finds, the consideration of archaeological interests in spatial planning as well as the guarantee that environmental impact statements and the ensuing decisions take sites of archaeological interest and their context into account.

- 1996 Charter on the Protection and Management of Underwater Cultural Heritage (ICOMOS Charter 1996) [42]: A supplement of the ICOMOS Protection and Management of Archaeological Heritage of 1990 [43]. It outlines the fundamental principles for UCH conservation, while it elaborates, among others, on issues of funding; research objectives; team members' qualifications; investigation, documentation and material conservation; management and maintenance of the $\mathrm{UCH}$ site; and dissemination of information about the UCH. It also encourages international cooperation and exchange of specialists in order for $\mathrm{UCH}$ research to be facilitated, while fostering public awareness with respect to the importance of $\mathrm{UCH}$ and the role of the public in its protection and investigation.

- 2001 UNESCO Convention on the Protection of Underwater Cultural Heritage [3]: Constitutes an international framework for the protection of $\mathrm{UCH}$ older than 100 years. It provides a definition for UCH, such as 'State vessels', which are warships, aircraft and other non-commercial vessels that are given cultural importance. It also ensures the rights of flag states to excavate and preserve these vessels beyond their territorial waters. More specifically, in Article 2, it sets out the rights of State vessels to be consistent with state practice and international law, including the UNCLOS, and claims that nothing in the convention shall be interpreted as modifying the rules of international law and state practice pertaining to sovereign immunities, nor any state's rights with respect to its state vessels and aircraft. The convention went beyond UNCLOS to set out the rights and duties of the coastal state and/or flag nation according to the location of the sunken $\mathrm{UCH}$ in the defined maritime zone. Furthermore, it uses the rules of the 1996 ICOMOS charter on the handling and management of $\mathrm{UCH}[44]$.

The above protection framework provides the basis for a preferable option of preservation practice of WW I and II UCH to be their "in-situ" handling by means of non-destructive techniques, non-intrusive survey and sampling in preference to their removal. Of importance are also developments and approaches/tools for such investigations of $\mathrm{UCH}$ and the gathering of empirical evidence from a number of case studies, which can form the ground for establishing guidelines for a more informed $\mathrm{UCH}$ management.

In the above considerations of WW I and II protection/preservation frameworks, there is a need nowadays to consider developments with respect to spatial planning in the marine environment in Europe. The European Union (EU) blue growth strategy for opening up economic opportunities offered by the sea, coupled with the Marine Spatial Planning (MSP) and Integrated Coastal Zone Management (ICZM) as proper planning tools for handling the spatial aspects of these opportunities, have brought on board new perspectives for the sustainable exploitation of marine resources. These evolutions are capable of tackling developmental perspectives and related environmental impacts in oceans and seas.

Based on the blue growth strategy as well as related policies and resources used for its implementation, the marine environment is gradually shifting to a place of opportunities and an attractive investment space for a variety of sectors, a fact that can generate opportunities but also threats to UCH. Coping with these opportunities and threats for planning the sustainable management of WW I and II UCH in the newly evolving marine environment implies additional challenges, while providing 
new meanings to concepts such as 'territorial governance', 'consultation' and 'public participation' embedded in MSP definition [45]. In fact MSP, under a place-based approach, can create better chances for WW I and II UCH protection/preservation and sustainable exploitation, provided that it can properly handle sectoral competition and respective maritime uses. Chances for sustainable management of WW I and II UCH are further enhanced when taking also into consideration the emphasis placed by the blue growth strategy on coastal and maritime tourism activities; and the sustainable exploitation of the competitive advantages of European coastal destinations, emerging from their cultural richness and diversity as well as their global reach. Taking into account that MSP under a place-based approach has been gaining ground all over the world [46], and that the use of sea and coast for various recreational purposes is expected to become more intense in the future, the opportunities for sustainably exploiting WW I and II UCH could be a noticeable trend. The way such a trend will be exploited for serving developmental objectives largely depends upon the ways spatial planners and decision-makers will compromise on the pressures exerted by other sectors for maritime investments along the blue growth direction with $\mathrm{UCH}$ protection/preservation and sustainable exploitation objectives.

\subsection{Effectively Managing WW I and II UCH in the Mediterranean-Challenges and Opportunities Ahead}

This subsection elaborates on a range of important "glocal" challenges and opportunities, i.e., issues of global but also local (Mediterranean) concern. These, according to the authors' view, delimit successful WW I and II UCH management in the Mediterranean, an important WW I and II scene due to the large number of significant $\mathrm{UCH}$ at depths that are diver accessible in the warm and clear Mediterranean waters.

An in depth understanding of the WW I and II UCH legislative protection framework brings to the forefront a number of unique and challenging issues that are missing or not fully clarified or are even lacking uniformity among legislative initiatives of different states. These need to be further explored in order for the protection and preservation of WW I and II UCH in the Mediterranean to be effectively accomplished.

A critical question for WW I and II UCH preservation in this respect is who has ownership and responsibility in handling such WW military or 'state' vessels? Currently, there are conflicting and inconsistent WW I and II UCH protection frameworks among global, transnational (Europe), and national entities. There has been much discussion in the literature concerning legal ownership of military sunken vessels and their remains [20,44,47,48]; and the recognition of sovereign immunity of warships depends on continued ownership of the sunken vessel by the flag nation. One question raised is 'What happens if UCH of one nation falls into the waters of another nation?' [4]. Practically speaking, in many cases there is no consistent practice in determining whether the flag nation has abandoned a vessel; and, as a result, the coastal state, in the waters of which the vessel lays, can undertake any kind of action. Governing international laws can be really problematic in their interpretation with respect to such a context [48].

It should also be noted that some WW I and II sunken vessels are located in historical battlefield areas that are designated today as military zones, prohibiting public access; and are protected by the military service in many Mediterranean countries (e.g., Gallipoli-Marmara). For this type of UCH, a number of unique challenges emerge as far as its preservation is concerned. Particularly for WW II vessels, the most important refer to safety issues with regards to munitions and risks to diver safety; potential environmental pollution from munitions, hazardous cargo, fuel and other materials on wrecks, especially those fueled by oil, in contrast to WW I vessels that were coal-fired $[4,20,48,49]$. The corrosion of metal wrecks from this era however can, depending on their construction materials and containments, act as either a cause for marine pollution, i.e., a threat to the environment; or as a beneficial factor, facilitating the formation of artificial reefs that colonize marine organisms and sea-life.

Identifying the way WW I and II vessels act in the marine environment is important for both their preservation and protection of their surrounding environment, since these are made of low-carbon steel or aluminum, which rapidly corrodes in saline water depending on the burial environment, and 
many contain tons of fuel [50,51]. Repercussions of climate change, e.g., increasing temperatures and acidity of the marine environment, can worsen their stability. This is the case of the Mediterranean Sea, perceived as a highly vulnerable area to climate change impacts [11,52]. In this sea, other risks are inherent as well, for example, often these vessels suffer additional damage or losses due to natural causes, such as earthquakes, storms; but also due to human ones, such as salvaging for scrap metal, looting, damage from fishing trawlers to name a few.

Terrestrial archaeological sites are more easily accessible and managed, in contrast to UCH ones. In fact, accessing UCH sites is confronted by many risks and challenges, mainly due to difficulties of their surrounding (in many cases largely unexplored) environment, the marine one. This renders WW I and II UCH identification, documentation and preservation a complex task. A first critical issue, in this respect, is the lack of adequate knowledge as to the exact location of WW I and II UCH. In fact, there are numerous sunken vessels in the Mediterranean, the exact location of which is yet unknown. Geo-localization of potential underwater archaeological sites and related UCH deposits (sunken wrecks) needs to be undertaken.

In this respect, development of proper tools and technologies for identifying and assessing UCH sites (see e.g., [53]) seems to be a primary step in order for performance and operational applications for monitoring and management of $\mathrm{UCH}$, including discovery, documentation, risk monitoring and preservation of heritage sites, to be advanced [54,55]. To this end, researchers are nowadays largely supported by the state of the art developments in underwater technology that support them in conducting survey, identification, navigation, excavation, documentation, restoration, and conservation of UCH. In addition, various options and systems are nowadays available for high-quality UCH mapping and extensive photographical documentation, such as 3D LiDAR underwater laser systems, remotely operated vehicles (ROV) [56], remotely controlled underwater robots, high-resolution acoustic sensors like the synthetic aperture sonar (SAS) technology [57] to name a few. Remarkable progress is also noticed in technologies that support wider communication of $\mathrm{UCH}$ objects to the public, e.g., Virtual Reality (VR) technologies and the latest three dimensional (3D) reconstruction techniques [58,59].

Of importance is also the prevailing approach for $\mathrm{UCH}$ protection/preservation, which is mainly represented by the archaeological/historical viewpoint. This is framed by the respective protection legislation and research that mainly focuses on documentation/mapping of $\mathrm{UCH}$ as well as understanding the condition and formation of the site, i.e., the tangible $\mathrm{UCH}$ aspects, placed within the wider environment for preservation [60]. To fully grasp the UCH and surrounding site, research usually involves creation of inventories as well as building of local research and protection capacity, when possible. There may be even public awareness campaigns associated to these sites, but usually exploitation plans in making sites visible and/or accessible to the public may not be a prior concern due to the reluctance of scientific personnel involved or lack of the necessary funding. This "silo" approach, i.e., a mono-disciplinary consideration of $\mathrm{UCH}$ that is mostly taken by marine archaeologists or heritage professionals, implies that UCH lacks a substantial link to society and its interpretation as a valuable cultural resource that can steer sustainable development objectives.

This missing link has so far deprived a more integrated UCH management approach in the Mediterranean, conceiving UCH as a pillar for reaping economic and societal benefits. The 'silo' approach is worsening when heritage professionals operate as a sole player and refuse to collaborate with professionals from different fields or agencies. Nutley (2017) [6] provides a good account for the need of a multi- and interdisciplinary cooperation in the $\mathrm{UCH}$ management field, stressing the importance of interpretation as a fundamental first step for $\mathrm{UCH}$ management and raising the question of ' $w h o^{\prime}$ has the responsibility to provide this interpretation. He claims that widening the viewpoints of interpretation can add value to $\mathrm{CH}$ management and increase its very essence, i.e., imparting values and meanings this carries to society and future generations, and act as a catalyst for social cohesion and identity building.

World-wide, there have been fragmented efforts to preserve WW I and II UCH sites in-situ, and usually only for UCH associated to a famous battlefield narrative (D-Day beaches, France; Truk Lagoon, 
Micronesia-Figure 3; Pearl Harbor, USA). Preservation of such UCH is directly linked to its exploitation by building a narrative that attracts the public's interest and concern, which motivates its sustainable management. Speaking of the WW II UCH narrative of the Mediterranean, it should be noted that this remains unexploited by local communities and/or coordinated national agendas, in contrast to other parts of the world; while little or no efforts are placed on its preservation. Recent projects attempt to map such wreck sites [61] and create relevant databases (e.g., [62]). However, the Mediterranean region has not been a priority in these efforts, since archaeologists from this region place more emphasis on ancient sites as opposed to wrecks from this era. The main reason may be that they are not considered as important to investigate as other unknown UCH sites from other eras, since WW I and II wrecks and their associated events may already have considerable amounts of historical documentation [63]; or they are relatively recent, particularly compared to other shipwrecks found in the Mediterranean. Documentation and monitoring of the condition of these highly vulnerable $\mathrm{UCH}$ sites are critical for their conservation assessments, while preservation plans need to be devised so that they will not become lost forever.

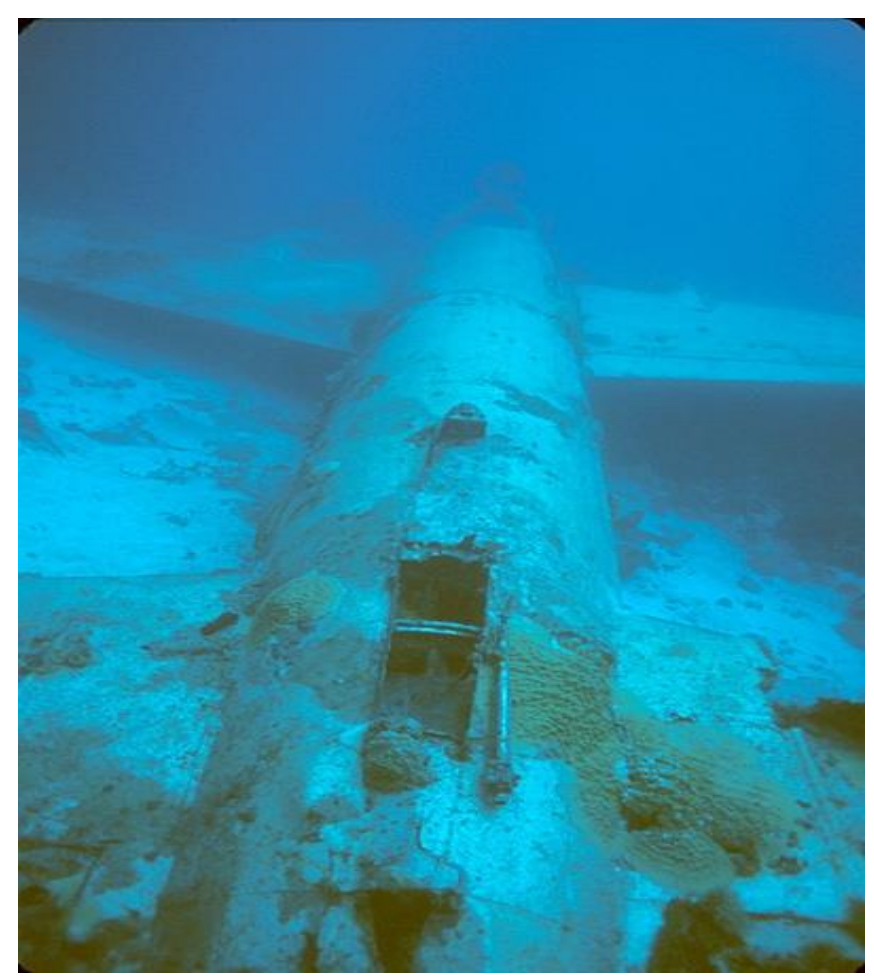

Figure 3. WW II—Pacific Theater Truk Lagoon, Micronesia-Mitsubishi G4M1 ("Betty"), Photo credit 1849 Aquaimages, Licensed by CC BY-SA 2.5 .

Another issue of decisive importance, especially for the preservation of WW II UCH, relates to the provisions established by the international protection framework of UNESCO 2001 [3]. This framework covers only WW I UCH protection (UCH more than 100 years), while leaving aside WW II UCH, being less than 100 years old. Due to this provision, many countries have not signed this convention as it, among other reasons, conflicts with their own national laws and/or beliefs on treatment of human remains associated to the $\mathrm{UCH}[4,20]$. Additionally some countries, Greece for example, protect $\mathrm{UCH}$ less than 50 years old, such as WW II wrecks [64]. This means that public access to them requires permission from the Ministry of Culture; and for sovereign immune vessels from the respective foreign authority (owner) or the Greek Ministry of Defense, if it is a Greek military vessel. Other countries, like France, do not protect WW II marine sites as UCH, but national legislation prohibits looting from such sites. In the European Union, there is still no common ground among its member states as to the 
protection and recognition of such UCH. In fact, most EU nations lack common and integrated policy frameworks on handling such $\mathrm{UCH}$; while still missing is also the integration of $\mathrm{UCH}$ preservation into the design of other, mainly sectoral, policies, e.g., tourism and fishery policy, questioning thus even the safety of $\mathrm{UCH}$.

\subsection{Successful WW I and II UCH Sustainable Management Practices in the Pacific}

As good examples of UCH preservation and sustainable management can be mentioned the WW I and II marine sites in the Pacific. The marine sites of the 'Pacific Theater' of WW II are battlegrounds in the Pacific and Asia, where Allies fought against the Axis forces, beginning with the bombing in Pearl Harbor by the Japanese on 7 December 1941. These sites have so far been more intensely researched, while they attract substantial cultural tourism to their famous wreck sites [24].

The most visited site is the battleship USS Arizona [50], which sank in Pearl Harbor, Hawaii, on that infamous day resulting in 1177 American casualties. A visitor center is situated on the surface over the wreck, which acts as a memorial, once drawing as many as 1.8 million visitors a year (no public diving is allowed on this wreck and currently the visitor center is closed) [65].

Another sustainably managed popular WW II battlefield tourism destination is Chuuk Lagoon, a globally well-known diving location. There are over 50 WW II wrecks in the sites of Chuuk, being the result of a 1944 battle between the Americans and the Japanese, who used the islands as a major military base. This battle resulted in over 4000 Japanese causalities. Jeffrey (2017) [66] describes that both the underwater and the terrestrial sites related to WW II are exceptional in quantity and quality. With the warm, clear waters of the lagoon, the $\mathrm{UCH}$ is considered one of the great 'undersea' wonders of the world.

There have also been recent efforts to develop UCH tourism in Saipan by establishing a Heritage Trail for the island, based on a collaborative effort including local community, academia, non-profit organizations, and government agencies [67]. The UCH on the islands Saipan and Northern Marianas (Guam and Tinian) was the result of the Americans taking over these Japanese-held islands in 1944 to establish their base near Japan.

However, by far the best example of management plans for shipwrecks is in Australia, which considers MSP [68,69], and involves public access and engagement to its UCH sites. Approximately 8000 shipwrecks have been documented, including from WW I and WW II that sank around their coastline; and only 22 are located within protected zones, requiring a permit to access the site [8]. Viduka (2017) [8] describes the important role that community groups play in Australia's maritime heritage management, supporting search and discovery of wrecks in Australia.

Both the US National Oceanic and Atmospheric Administration (NOAA) and the Historic Shipwreck Program in Australia have established individually and, in some cases, jointly UCH Resource Management Activities in the Pacific Region [8,65]. They jointly have a Memorandum of Agreement in the discovery of US ships, which were lost in the Battle of the Coral Sea, Lexington, Neosho and Sims, and were declared protected historic shipwrecks on the 70th anniversary of their loss on 7 May 1942 [8]. Their programs provide interpretation, protection, and preservation of these WW I and II UCH sites. The work often involves multi-stakeholders' driven research to highlight the diversity of research interests and priorities involved; and uses in many cases, telepresence technology as well as a live internet feed for public participation [63]. All management plans have a common perception as to the role of local people as the most important site managers, while getting support by those who have vested interests [66]. Since the 1980s there have been many surveys of WW II UCH sites in the Pacific, including corrosion studies of the wrecks in order for the time of collapse of the structures to be estimated; and spillage of their fuel to be assessed for grasping potential environmental impacts [50,51]. Other safety (e.g., danger of unexploded ordnance) and ethical (e.g., site is a maritime grave) issues have been dealt with by enlisting some WW II UCH sites in protected zones, where public access is not allowed without permit [8]. 


\section{Open Issues for WW I and II UCH Preservation and Sustainable Management in the Mediterranean}

"UCH holds the history of the planet and human civilization that is now underwater. It has a cultural significance as well as a conservation dimension and offers great potential for sustainable tourism and income-generation for local communities." This statement, articulated in the Side Event on 'Safeguarding Underwater Cultural Heritage for Sustainable Development' by Ms. Nisha, UNESCO's Director and Representative to the Pacific States [70], features the glocal nature (global and local) of UCH, which is justified by its significance for:

- comprehending and preserving the 'big image', i.e., the historical memory of world's past failures or progress through the social, economic, and technological information UCH conveys [47], and imparting this image to future generations; and

- $\quad$ exploiting UCH potential to leverage local development in small islands and/or island states as well as peripheral coastal regions by drawing qualitative, long lasting, blue growth-driven, heritage-led development pathways.

The noticeable significance of UCH in general, but also WW I and II UCH in particular, being the focus of discussion in this paper, brings to the forefront two highly complex and interwoven goals, namely WW I and II UCH protection/preservation; and its integration into local development planning endeavors in coastal and insular communities in the Mediterranean region.

Achievement of these goals, according to authors' perception, implies the transition from a "silo" to a more integrated and cooperative UCH management approach, embedding heritage managers' work into a cultural planning process. Key aspects of such a transition, delimiting the context of the planning process, are discussed in the following, taking into consideration that although not all of these aspects are of strictly Mediterranean concern or decision-making, they however are perceived as crucial for sustainably managing Mediterranean WW I and II UCH, an important part of the world's heritage but also a valuable resource for heritage-led local development in this economically stagnating though culturally vibrant part of the globe.

\subsection{From a "Silo" to an Integrated WW I and II UCH Management Approach}

Marine archaeologists and heritage professionals -the main actors of the UCH "silo" approach, with this community perceiving themselves as "owners" of UCH [6]—are having a rather narrow viewpoint of $\mathrm{UCH}$ management, focusing on $\mathrm{UCH}$ location (where?), identification/documentation (state of preservation sites and materials), preservation options (e.g., in-situ) and monitoring of the site (site conditions-downscaling, stabilization of the site and recovered artifacts it contains) and its wider environment (open water conditions-upscaling) in order to ensure that the site will not be lost. This "silo" approach has been largely criticized for lacking a broader perspective of sustainable exploitation of $\mathrm{UCH}$, not fully addressing this heritage to society and sustainable development [71,72]. In fact it largely ignores that "cultural heritage is a shared resource, and a common good" [73] (p. 2); and that there is a need to incorporate in UCH study other skills, views, interpretations and perceptions as well.

However, during the last decade, a growing importance is attached to $\mathrm{CH}$ in general and $\mathrm{UCH}$ in particular, and an effort is carried out towards linking them to societal and local development objectives, further enhanced by relative policy initiatives. Blue growth strategy [74] and the strengthening of interest in coastal and maritime tourism is a remarkable example of such initiatives, setting this type of tourism as one of the five focus areas for delivering sustainable growth and jobs as well as social and economic cohesion in the blue economy context [75].

This in turn implies that in order for WW I and II UCH protection/preservation and UCH-driven Local Sustainable Development (LSD) goals to be achieved, a certain shift from the "silo" to a more integrated approach (Figure 4) is gradually becoming apparent [73]. Such a shift is expected to support achievement of the above goals by properly integrating: 
(i) UCH management dimensions into various contexts (e.g., spatial, environmental, economic, societal), thus constituting a step towards a multi- and inter-disciplinary interaction and cooperation among a variety of disciplines. This will bring on board diversified qualities and knowledge stock that are necessary for ensuring both protection/preservation and sustainable and resilient exploitation of WW I and II UCH.

(ii) Experiential knowledge and stakes of the various interested parties into scientific knowledge and decision-making processes, in an effort to create value and effectively protect $\mathrm{UCH}$ (good example of public engagement is the one of Australia, as presented by Viduka (2017) [8]).

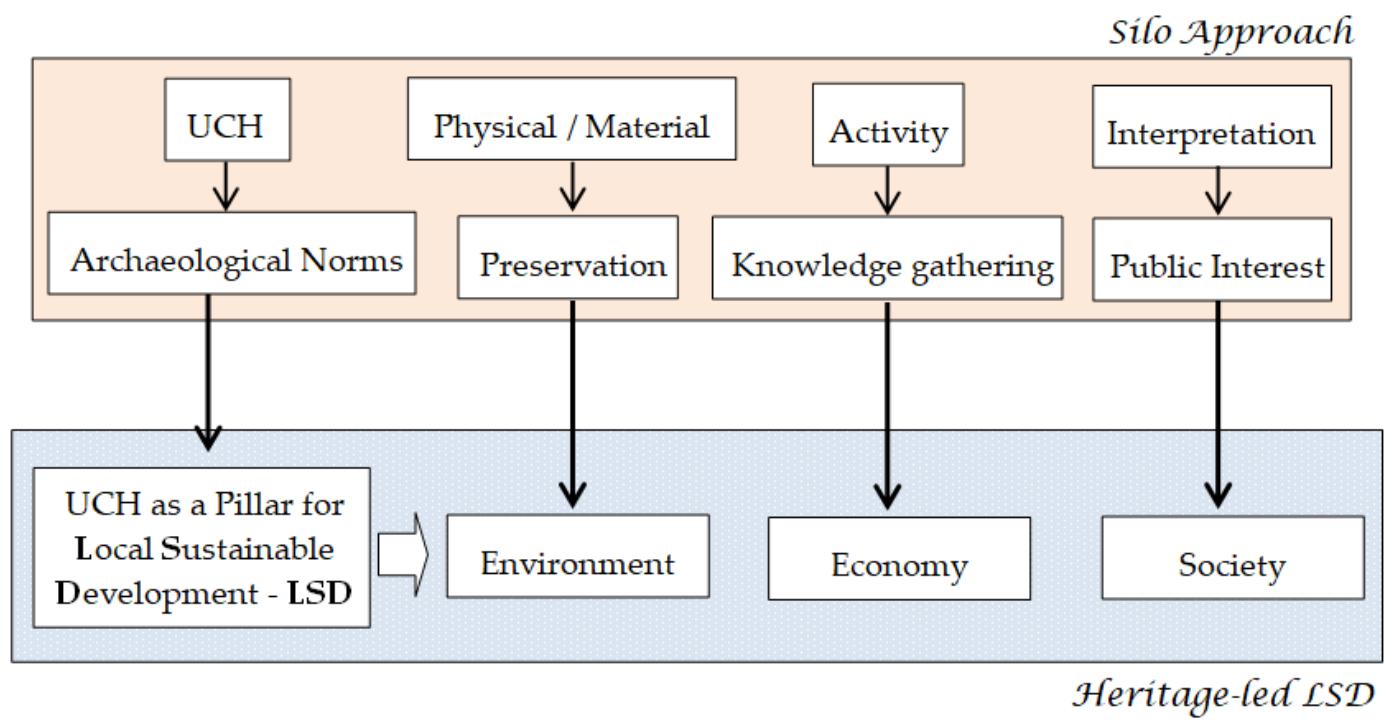

Figure 4. Linking underwater cultural heritage (UCH) management to sustainable local development-From a "silo" to a heritage-led Local Sustainable Development (LSD) approach, adapted from [60].

Touching upon all three pillars of current sustainability concerns - environment, economy and society/culture-such a newly engraving, integrated and comprehensive approach to UCH management (Figure 4):

- Places UCH in its wider environment, exploring positive and negative interactions of UCH with this environment. This implies the exploration and documentation of this interaction by means of an Environmental Impact Assessment (EIA), setting the ground for identifying risk or opportunity emanating from $\mathrm{UCH}$, i.e., $\mathrm{UCH}$ as a source of pollution [76,77] or an artificial reef [78,79].

- Grasps UCH as a valuable resource, a production factor, which can create positive impulses to local economies by opening up business opportunities for new cultural experience-based products and local income creation $[7,80]$. This view is further enhanced by the EU blue growth strategy [81,82], fertilizing the ground for the attraction of investments in maritime activities. Sustainable exploitation of UCH has definitely the potential to be part of a vibrant blue growth strategy of EU, provided that the carrying capacity of the seascape is consciously addressed. Thus, $\mathrm{UCH}$ sites are potential places for sustainable experience-based tourism development, playing the role of e.g., underwater museums of the European history, but also sites of recreation and leisure in properly managed underwater parks and diving trails. These can render these historical maritime landscapes and their content visible and graspable to a larger audience.

- Engages society in the creation of a UCH narrative that embeds empirical knowledge and has multiple benefits with respect to local identity building, awareness raising on the value of $\mathrm{UCH}$, establishment of community bonds and promotion of social cohesion and people's sense of 
belonging $[42,83,84]$. WW I and II UCH sites incorporate significant evidence of past military and fatal events and disasters that are closely related to their wider land neighborhood and are strongly linked to historical trajectory and socio-cultural aspects of local communities. In this respect, these are perceived as integral parts of local identity and incorporate meanings and values for these communities. Shifting to an integrated UCH management approach implies additionally the establishment of new trails for spreading these values to society and economy in an environmentally and culturally responsible way, safeguarding thus $\mathrm{UCH}$ and paving the way to heritage-led LSD [6]. In contrast to the view of Hannahs (2003) [85], stating that public access to archaeological sites is both incompatible with and contradictory to the goal of their preservation, many researchers share the opinion that when $\mathrm{UCH}$ is discovered, it should be properly managed, taking into consideration the needs of science and of the public, within the context of the prevailing legislative framework. Scott-Ireton (2007) [86] takes it a step further by designating community involvement as a critical factor for the successful management of submerged archaeological sites; but also a key driver and an effective means for monitoring shipwrecks in the community's own backyards, providing more effective results than legislation and threat of arrest per se. Training people to respect $\mathrm{UCH}$ and teaching them to perceive this heritage as a historical asset determining their identity, but also a resource that can steer new economic opportunities, and a catalyst for social cohesion and environmental sustainability, can strengthen public awareness and render local communities the safeguards of this heritage to the benefit of sustainable local development.

The broadened UCH management perspective for heritage-led LSD, promoted during recent years, is also advocated by Altvater (2017) [87], who states that UCH sites should be interpreted as multifunctional sites, embedding environmental, economic, socio-cultural/historical and spatial dimensions; while their management needs to be perceived through an integrated and holistic UCH approach. Heritage managers in such an approach, apart from their traditional role as leaders of UCH protection/preservation processes, should in addition act as facilitators in orchestrating interaction among all those who can have a 'say' in the sustainable exploitation of $\mathrm{UCH}$, setting also exploitation constraints in alignment with UCH carrying capacity.

\subsection{Dealing with WW I and II UCH Management as a "Wicked" Planning Problem}

The goals of WW I and II UCH protection/preservation and its integration into local development planning endeavors in coastal and insular communities in the Mediterranean region represent the two sides of the same coin and compose, in terms of planning terminology, a "wicked problem" [88]. This is due to the very nature of WW I and II UCH as part of the cultural heritage, and the multiple scientific dimensions it encompasses, such as [7]:

- Purely technical: Archaeological and heritage management approaches for UCH protection/preservation.

- Environmental: Role of UCH as either a pollution source or a beneficial artificial reef.

- Social and ethical: UCH linkages to diversifying localities' values and narratives or human losses of varying nationalities.

- Technological: Tools and technologies addressing UCH research issues.

- Jurisdictional: National and international laws and conventions dedicated to UCH protection.

Apart from the above dimensions, effective $\mathrm{UCH}$ management should also take into account the different stakes of parties' interests in $\mathrm{UCH}$, as well as the diverse understanding or multiple meanings attached by these parties to both the UCH per se and its surrounding environment, together with their power to influence UCH management decision-making processes. This implies the full understanding of the multiplicity of cultural cognition and the setting of cultural $\mathrm{UCH}$ management into the diverse and multi-faceted constructed social contexts [89], steering thus a culturally-sensitive and informed $\mathrm{UCH}$ management approach. Here, special attention is needed with respect to 'dissonant heritage', implying the often different meanings, values, and interpretations attached to WW I and II UCH and 
the potential conflicts these can create, e.g., between tourism and sacred use of the site or between local and global perspectives [90]. As a result, there are often fragmented group histories related to WW I and II, such as national heritage that focuses on liberation or even defeat; ethnic groups that focus on deportation/execution in a specific place; soldiers from abroad that lie in war cemeteries on land or in $\mathrm{UCH}$ that are important commemorative places transcending the narrative of local ethnic groups [91].

The complexity of WW I and II UCH management for serving protection/preservation and sustainable exploitation purposes and the various concerns this entails is schematically designated in Figure 5.

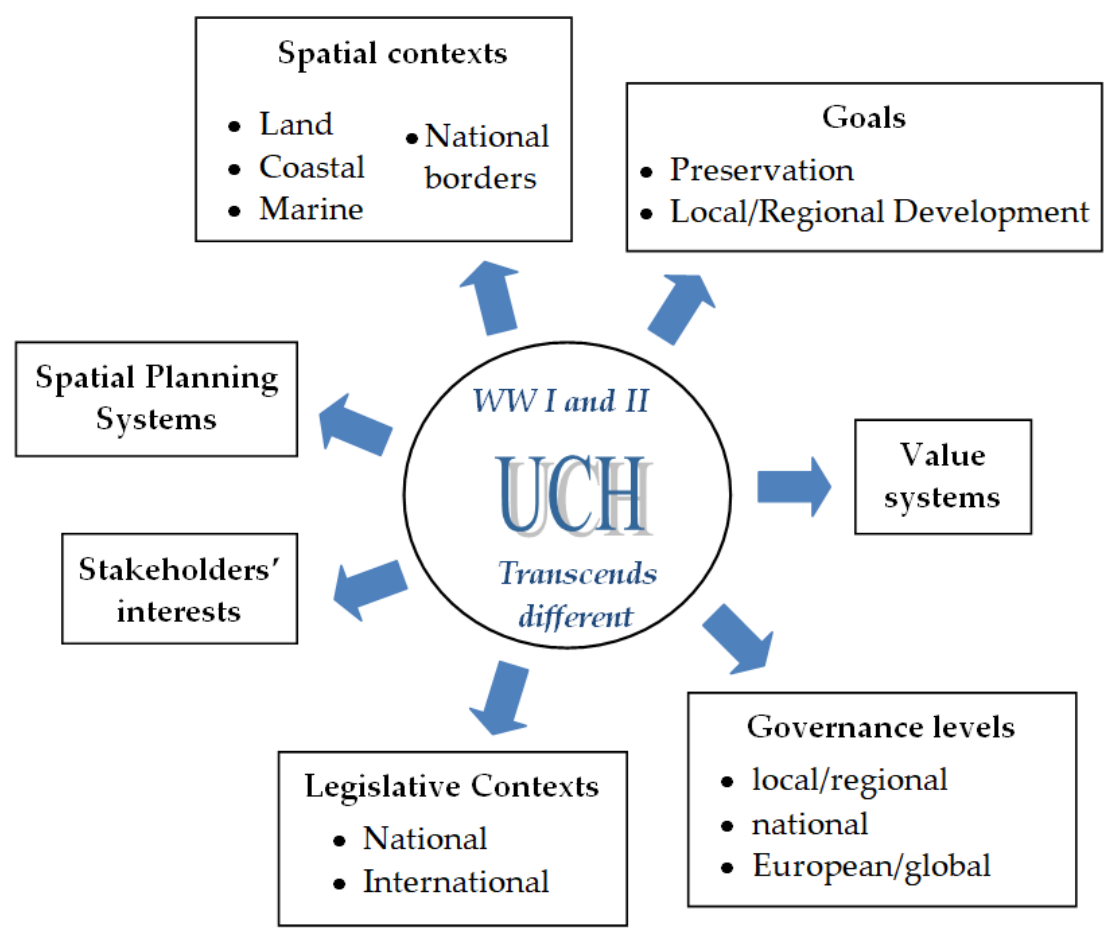

Figure 5. Context of WW I and II UCH sustainable management as a "wicked" planning problem.

Starting from the spatial context of WW I and II UCH, it is worth noting that although this heritage has a specific spatial reference, i.e., the marine environment in which it is found, and a specific location in this environment, its importance transcends also directly the (Figure 5):

- neighboring coastal part, since a number of wrecks are potentially located close to the coast and their narrative are strongly linked to the coastal part as well, such as the case of Southern France, and "Operation Dragoon" in WW II or the case of Leros Island, Greece and 'The Battle of Leros' in WW II; and

- neighboring terrestrial part of the area through e.g., the involvement of local population in the military events or the location of military installations/operations in the land part, such as the case of Leros Island, Greece in WW II [7].

Apart from the above direct influence of WW I and II UCH on the coastal and terrestrial part, this can also impact these parts indirectly, through e.g., the cultural enrichment of respective localities or the deployment of coastal and land cultural planning interventions as counterparts of the sustainable exploitation of $\mathrm{UCH}$.

In spatial terms, $\mathrm{UCH}$ importance transcends additionally national borders, as there are an abundant number of WW I and II military vessels to be found in waters that differ from the flag of the vessel, thus flag nations have a 'say' in their handling. 
Another important issue for $\mathrm{UCH}$ management relates to the prevailing practice through which this heritage is currently handled, largely marked by a "silo" approach that is based on archaeological norms (Figure 4). This approach confines the goals of UCH management to protection/preservation, leaving aside concerns related to the sustainable exploitation of $\mathrm{UCH}$ for serving local development objectives as given in Figure 5 .

Speaking of the complexity of $\mathrm{CH}$ management, one cannot leave aside the issue of $\mathrm{CH}$ governance, i.e., a rapidly evolving area, and a multi- and inter-disciplinary research field [92] that, additionally, attracts the interest of a variety of stakeholders, e.g., institutions, administrative entities, societal and user groups; further reinforcing the complexity of $\mathrm{CH}$ management. In particular, $\mathrm{UCH}$ governance adds additional layers of complexity in this research area, mainly due to the peculiarities of the marine environment in which UCH lies; the competing and, many times, conflicting sectoral interests and respective maritime uses that can place $\mathrm{UCH}$ at risk; and, at most times, the limited accessibility for further research, management and monitoring of this type of heritage.

$\mathrm{UCH}$ governance implies horizontal but also vertical interactions among those involved in decision-making processes.

Horizontal interactions address linkages of UCH exploitation to coastal and land developments. Indeed, effective UCH management implies the need to adopt approaches that accommodate land and marine interactions; and lead to UCH preservation plans that are in alignment with a variety of terrestrial and marine legal frameworks and related policies. Difficulties inherent in such a task render policy making with regards to $\mathrm{UCH}$ a rather tricky issue, in contrast to policy making in terrestrial areas; while broaden the range of actors that need to be engaged in relevant decision-making processes.

Vertical interactions reflect the necessity for coordination among $\mathrm{UCH}$ policies articulated at different spatial decision-making levels (national, European, global). Design and enforcement of UCH preservation decisions is actually dispersed to a range of jurisdictions, with different and sometimes conflicting interests and perspectives; and at a variety of spatial scales, from local to global. This, coupled with the recently evolving paradigm towards an enhanced collaboration between public authorities as well as private actors and the civil society, renders $\mathrm{UCH}$ management a principally "cultural governance" topic. Governance in this respect targets the formulation and implementation of $\mathrm{UCH}$ policies that are inspired by the close interaction among a variety of actors, originating from the states or official organizations of European and/or global reach, the civil society and the cultural market.

The value of the participatory dimension of cultural governance is also highlighted by the European Council's conclusions of 26 November 2012 on "Cultural Governance", stressing the significance of making cultural governance more open, participatory, effective, and coherent [93]. Such a UCH consideration features the significance of coordinated actions of both vertical and horizontal nature that: result in a coherent UCH protection framework; adjust this framework to other sectoral policies affecting $\mathrm{UCH}$ activities (fishing, transport, tourism, diving, environment, offshore activities, etc.); ensure cooperation of different jurisdictions (e.g., national and local/regional administrations, archaeological institutions, EU institutions); and accommodate a variety of stakeholders' interests (e.g., academic and research institutions, experts, NGOs, NPOs and civic community representatives).

Speaking of the legislative context, it should be noted that enunciation of legal rules for WW I and II $\mathrm{UCH}$ protection is a quite complex issue, where the number, diversity and spatial reference of different bodies taking legislative action (from national to global level) leads to what Strati (1995) [47] calls a legal labyrinth, translated into a variety of wreck, salvage and heritage laws, which can differ among national legal systems.

The core legal issues in WW I and II UCH protection for a state are jurisdiction, ownership rights, and sovereign immunity $[20,44,94]$.

In the case of jurisdiction, WW I and II UCH may lie in disputed or international waters, rendering ownership of a submerged vessel rather unclear. Ocean politics and governance is often related to state priorities, including not only UCH but also an array of priorities, such as energy security, safeguarding national security and maritime interests [20]. 
Sovereign immunity or ownership of military vessels by flag states on the high seas may have been extinguished through abandonment by the flag state. However, determining when a military vessel has been abandoned can be problematic (e.g., through capture, agreement, gift or sale) [48]. Furthermore, the UNCLOS Convention does not include merchant vessels engaged in the war effort by a state and, more importantly, does not make specific reference to whether sunken vessels are still entitled to such immunity [20,44,48]. Strati (2006) [44] claims further that if a flag state has not enacted specific legislation to protect its $\mathrm{UCH}$ in the high seas, admiralty law may govern historic wrecks and their cargoes; and the finder may be considered as having a good right to such property, and may carry out salvage operations.

The UNESCO 2001 Convention for UCH, as briefly discussed in Section 3, has resolved many of the shortfalls of the UNCLOS Convention by clearly defining what are 'State vessels', i.e., warships and other vessels or aircraft that were owned and operated by a state and were used at the time of sinking only for governmental non-commercial purposes. However, the convention does not resolve the issue of sovereign immunity of sunken warships, since it was considered too complex from a technical and legal point of view; and the issue of UCH ownership still remains a gap in this convention [20,44]. More importantly, this convention only applies to UCH older than 100 years, such as WW I vessels and does not yet include vessels of WW II. Many states, such as Greece, Turkey, Japan, and United States, to mention a few, have still not signed this convention, since some of its provisions may be in conflict with their national laws or for other reasons $[4,20,44]$. Finally, issues on how to manage UCH that involve hazards from polluting or dangerous materials, which may be associated to these types wrecks, are not detailed in UNESCO's provisions [20,48].

Where the 1982 UNCLOS Convention fails to mention sunken warships, and states have not signed the 2001 UNESCO Convention, the US and other maritime powers, such as Japan, Netherlands etc. have made formal statements upholding the notion of sovereign immunity of their sunken warships [20], regardless of which maritime zone they are located in. However, the issue of sovereign immunity to sunken warships as well as the precondition of ownership and abandonment can still be problematic and unresolved, despite the provisions of these conventions and the formal national statements or laws. Strati (2006) [44] explains why the UNESCO Convention did not deal with the 'presumption of abandonment' for this type of $\mathrm{UCH}$, since this issue affects indirectly ownership. In this respect, it avoids the complex issues associated with ownership of the $\mathrm{UCH}$, since the legal status of historic shipwrecks and their cargoes are entangled with the various wreck, salvage, and heritage laws, which vary among different legal systems. Furthermore, she states that the absence of international principles on the question of ownership indicates the reluctance of the international community to regulate this issue, which is left open to domestic legislation.

Discussion on WW I and II UCH brings also forward the issues of 'value' and public importance of $\mathrm{UCH}$ that are critical for prioritizing decisions on $\mathrm{UCH}$ preservation and have been extensively discussed in the literature (e.g., $[5,86,95,96])$. As Pye (2001) [97] (p.57) states 'the meanings and values attached to objects ... provide the very reason for conservation'. Preservation of $\mathrm{UCH}$ is therefore perceived as a value-driven activity or an effort to maintain and enhance significance carried out by this part of $\mathrm{CH}$. This in turn brings to the forefront the issue of value judgment and the need to explicitly define and prioritize judgment criteria that reflect the different views and perceptions of the heritage object at hand. As such, the following can be indicatively perceived:

- Legislative status, e.g., abandoned/protected according to maritime laws;

- Vulnerability or risk to loss;

- Polluting source or artificial reef;

- Current condition of UCH;

- Role as historical prototype of ships and related technology that survive in a submerged museum-like status;

- War grave or memorial; 
- Political, economic, cultural/historical values UCH carries;

- Spatial attributes, e.g., location, sea depth, visibility and temperature of waters;

- Social value, i.e., sense of identity based on various perspectives (local, coastal state and flag nation perspectives);

- Symbolic value-conveyor of meaning.

By further enriching the above list, a clear cut, multiple perspective assessment framework can be produced, which can result in a transparent and fully documented preservation/prioritization scheme in support of decision-making and resource allocation with respect to $\mathrm{UCH}$ protection/preservation. Prioritization of judgment criteria in respective multicriteria assessments, i.e., attachment of criteria weights, is a matter of public and stakeholders' engagement in order for the different perspectives to be grasped and properly balanced. Expected challenges of important $\mathrm{UCH}$ that are prioritized rather low due to their dark or dissonant history they carry will need to be dealt with so that conflicting or ambiguous heritage values can be neutralized through either museumification or commemorative conversion of the site [98] (see [98] as case study example).

\subsection{UCH Management Concerns in the Mediterranean Region}

As can be inferred by discussion in the previous sections, WW I and II UCH protection/preservation as well as planning efforts for its sustainable exploitation in the Mediterranean have to be accomplished in a decision-making environment that is full of uncertainties, risks, constraints and contradictions [99]. Moreover, this environment is rapidly evolving in natural, economic, social, technological, legislative, etc. terms. Some important issues that, according to the authors' perception, can influence UCH developments in the Mediterranean region are as follows:

- The marine environment in the Mediterranean is largely exposed to global challenges, such as the climate change $[100,101]$. In fact, as various studies demonstrate, the Mediterranean region constitutes a hot spot with respect to, among others, climate change impacts $[11,52,102]$, with these impacts creating a natural environment that places UCH stability at risk. The climate change strategy of EU and its member-states is considered as a positive step in coping with these risks, provided that $\mathrm{UCH}$ provisions are also incorporated in this strategy (ies).

- A debt crisis is unfolding in the Mediterranean during the last decade, implying that WW I and II UCH protection/preservation has to be carried out in an era of limited financial resources. In such a context, and taking into consideration the vast number of WW I and II UCH sunk in this area, valuing the importance of this UCH by developing a value/significance typology is quite critical for supporting more informed decision-making with respect to $\mathrm{UCH}$ protection/preservation priorities and rational use of resources. Within this stagnating economic environment though, there is an increasing stakeholders' interest for investing in a range of maritime sectors -the comparative advantage of the Mediterranean region- being the result of the rising new wave, i.e., the 'Blue economy', and the European policy initiatives (Blue Growth Strategy) towards the sustainable management of marine resources. This brings to the forefront new developmental opportunities in, among others, the tourism sector in coastal and insular areas in the Mediterranean [103]. Indeed, sustainable and resilient exploitation of WW I and II UCH in this region can strongly be linked to alternative tourism, e.g., dark/battlefield, cultural or diving tourism. Diving recreation activities, for example, present a promising activity at the global level, as noticed by the Recreation Scuba Training Council Europe-RSTC and evidenced by certification statistics provided by the Professional Association of Diving Instructors, i.e., the world's leading scuba diver training organization $[104,105]$. Furthermore, the linkage of UCH to alternative tourism is currently being met in many places around the world and is rated high in the policy agenda of urban and regional destinations [106] (see also experience from battlefield tourism destinations in the Pacific). Additionally, this is justified by the endurance of culture and tourism 
in times of recession [107], a current state in many Mediterranean countries nowadays; and their multiplier effects for local economies as a whole.

- UCH exploitation is in alignment with the current trends and related policies in promoting the culture-tourism complex (e.g., Regional Innovation Strategy for Smart Specialization-RIS3) [108], in order for sustainable pathways through experience-based and of low ecological footprint tourism products to be established; while supporting the exchange of new, meaningful and authentic tourism experiences [80]. The role of $\mathrm{UCH}$ in providing this type of experience was noticed early enough by ICOMOS (1996) [42], stating that if UCH is sensitively managed, it can play a positive role in the promotion of recreation and tourism.

- The technological environment is also rapidly evolving and is marked by progress conducted in tools and technologies for UCH identification, monitoring, visualization etc. that facilitate $\mathrm{UCH}$ research as well as communication of UCH content to a larger audience (see Section 3.2).

- Developments in the legislative context that relate to the management of marine space are in progress in the Mediterranean countries, coupled with relevant planning tools (Marine Spatial Planning-MSP and Integrated Coastal Zone Management-ICZM). These prepare the ground for dealing with emerging conflicts and promoting synergies' creation among various stakes in the marine environment; while setting up an effective spatial delineation of maritime uses to the benefit of $\mathrm{UCH}$ protection. However, a range of barriers appear in such a context as well, reflecting the different MSP systems of each single state involved; the stage of maturity of MSP in the various coastal states surrounding the Mediterranean Sea; the way UCH is handled within MSP studies; the provision of designated areas for UCH protection in each MSP system; and the national legislative regime as to the protection of $\mathrm{UCH}$, to name a few.

- Active contested and dissonance heritage issues related to $\mathrm{UCH}$ are of key importance, especially for South Eastern Europe (Balkans) and Eastern Mediterranean (Greece, Turkey, Middle East). This is justified by the multicultural background of Mediterranean region (Muslims, Christians, and Jews), but also its intense historical profile depicted through numerous wars, occupations, political turnovers and social changes (e.g., colonialism, WW I and II, fascism, resistance, civil wars, communism, ethnic cleansing to name a few) $[109,110]$.

\section{Conclusions}

The Mediterranean Sea or 'Mare Nostrum' is for many people a very special region of the world in many respects, e.g., natural, cultural and historical, commercial, climate. Being at the crossroads of three continents -Europe, Africa, and Asia- its geographical particularity is considered as a key driver for intensive cultural creation and diversity, marking developments in this region throughout the centuries [11]. Its impact on shaping the so-called Western world through time is also well established, both in society and in academia [111].

Many researchers also share the view that the Mediterranean is an Open Museum of the European identity and history in terms of, among others, its pivotal role played in WW I and II as a main 'theater' of fatal war events. This role is largely witnessed by the abundance of underwater remnants that rest in peace at the bottom of this sea [34,35]. Following the wording by Strati (1995) [47], stating that even the most disintegrated shipwrecks are time capsules full of human history, one realizes the importance of WW I and II UCH in the Mediterranean region for preserving, studying and reconstructing past historical events as well as spreading lessons learnt for building up peaceful, creative, and inclusive future development trails in this part of the world and Europe in general.

Exploration carried out by authors in developing this article has reached the conclusion that the "Mediterranean Theater" of WW I and II is a story yet largely untold, fragmentarily studied through 'silo' approaches, unknown to a wide audience, and not fully explored and documented. Moreover, the authors claim that this is a fascinating story and a real challenge in terms of collaborative endeavors needed, taking into consideration the complexity of both the spatial context concerned, i.e., the Mediterranean region, and the specific theme within this context, namely WW I and II sunken 
vessels. In the effort to work out the different dimensions of this theme, the authors do not propose solutions but principally identify gaps, i.e., open or yet not fully tackled issues, which need to be addressed in order for this sea graveyard to be shifted to a place of memory and experience-based cultural recreation, based on the abundant $\mathrm{UCH}$.

Filling these gaps and establishing the narrative of the WW I and II "Mediterranean Theater" can positively impact both the protection/preservation of these valuable, non-renewable and endangered $\mathrm{UCH}$ resources; and the local/regional development and blue growth objectives in the region by capitalizing on WW I and II UCH cultural, environmental, social and economic value.

The current external policy making environment is favorable for reaching both of the above goals. Indeed this is marked by the value attached to culture and cultural experience-based activities; the protection frameworks undertaken by various states that open up certain opportunities for sustainably exploiting $\mathrm{UCH}$ (e.g., battlefield grounds, diving marine parks); the directions of the blue growth economy and MSP/ICZM as supporting planning tools, which can enable the demarcation of UCH protected areas and activities that can take place in these areas; the emphasis of RIS3 on the promotion of the culture/tourism/ICT complex; the law enforcement of public engagement in (cultural) planning and management endeavors as well as in MSP, to name a few.

Experience and mutual understanding gained by the collaboration, in this article, of authors of different backgrounds -a heritage scientist and a spatial planner- has revealed the value added by removing 'silo' thinking and approaching this topic in a more integrated way. This, coupled with previously described exploration, have further advocated the necessity for broadening interaction in this field by establishing linkages and bridges between different viewpoints, stakes, decision-making levels, research directions, etc. so that synergies and more holistic views can be generated, thus effectively embedding the different perspectives to the topic at hand.

The range of issues relevant to the preservation and sustainable exploitation of WW I and II $\mathrm{UCH}$ that this article attempts to open up for discussion and further elaboration in the scientific and civil community clearly demonstrates the complexity of this task. It also reveals that dealing with preservation and sustainable exploitation of WW I and II UCH goes hand in hand with gathering of intelligence and distributed knowledge from a variety of sources, scientific disciplines, and communities. Furthermore, experience gained by exploring the context of WW I and II UCH in the Mediterranean region reveals the necessity to adopt value/people centered, locally adjusted, participatory spatial planning approaches that fit best into the long tradition of this region towards diversity and respect of human rights, democracy and participation. Protection/preservation and sustainable exploitation of $\mathrm{UCH}$, coupled with the exceptional natural heritage of the Mediterranean Sea, can form the foundations for entrenching sustainable, human-centric, long term and sea-based future development paths of this part of the world and its abundant coastal and insular localities.

Author Contributions: Both authors have equally contributed to this research article, representing a substantial attempt for people from different disciplines to interact and creatively collaborate on the topic.

Funding: This research received no external funding.

Acknowledgments: The authors wish to thank the reviewers for their detailed and constructive comments, which have contributed to the improvement of this article.

Conflicts of Interest: The authors declare no conflict of interest.

\section{References}

1. UNESCO. Underwater Cultural Heritage from World War I. In Proceedings of the Scientific Conference on the Occasion of the Centenary of World War I, Bruges, Belgium, 26-27 June 2014; Guérin, U., da Silva, A.R., Simonds, L., Eds.; UNESCO: Paris, France, 2015.

2. Snyder, K. Clipperton Project Saving the Oceans, One Person at a Time. Available online: http://www. clippertonproject.com/oceans-have-more-historical-artifacts-than-all-museums-combined/ (accessed on 1 February 2019). 
3. UNESCO. The UNESCO Convention on the Protection of the Underwater Cultural Heritage (CPUCH); UNESCO: Paris, France, 2001; pp. 1-40.

4. Delgado, J.; Varmer, O. The Public Importance of World War I Shipwrecks: Why a State Should Care and the Challenges of Protection. In Proceedings of the Scientific Conference on the Occasion of the Centenary of World War I, Bruges, Belgium, 26-27 June 2014; Guérin, U., da Silva, A.R., Simonds, L., Eds.; UNESCO: Paris, France, 2015; pp. 105-116.

5. Jameson, J.H.; Scott-Ireton, D.A. (Eds.) Out of the Blue; Springer: Boston, MA, USA, 2007.

6. Nutley, D.M. Look Outwards, Reach Inwards, Pass It On: The Three Tenures of Underwater Cultural Heritage Interpretation. In Out of the Blue; Springer: Boston, MA, USA, 2007; pp. 33-51.

7. Koutsi, D.; Stratigea, A. Unburying Hidden Land and Maritime Cultural Potential of Small Islands in the Mediterranean for Tracking Heritage-Led Local Development Paths. Heritage 2019, 2, 938-966. [CrossRef]

8. Viduka, A.J. Protection and Management of Australia's Second World War Underwater Cultural Heritage. In Safeguarding Underwater Cultural Heritage in the Pacific; PUCHP, Ed.; UNESCO: Paris, France, 2017; pp. 77-92.

9. Europeana 1914-1918. Available online: https://www.europeana.eu/portal/en/collections/world-war-I (accessed on 8 May 2019).

10. Timmermans, D. UNESCO Education Initiative-Heritage for Dialogue and Reconciliation: Safeguarding Underwater Cultural Heritage from World War I. In The Underwater Cultural Heritage From World War I UNESCO the Protection of the Underwater Cultural Heritage United Nations Educational, Scientific and Cultural Organization with the Support of Proceedings of the Scientific Conference on the Occasion of the Centenary of World War I; Guérin, U., da Silva, A.R., Simonds, L., Eds.; UNESCO: Paris, France, 2015; pp. 172-181.

11. Stratigea, A.; Leka, A.; Nicolaides, C. Small and Medium-Sized Cities and Insular Communities in the Mediterranean: Coping with Sustainability Challenges in the Smart City Context; Springer: Cham, Switzerland, 2017; pp. 3-29.

12. Porch, D. The Path to Victory: The Mediterranean Theater in World War II; Farrar, Straus and Giroux: New York, NY, USA, 2004.

13. Garland, A.; McGraw, H. The United States Army in World War II: The Mediterranean Theatre of Operations: Sicily and the Surrender of Italy; Center of Military History United States Army: Washington, DC, USA, 1993.

14. Miller, M.B. Sea Transport and Supply-1914-1918. Available online: https:/encyclopedia.1914-1918-online. net/article/sea_transport_and_supply (accessed on 7 February 2019).

15. Mills, S. HMHS Britannic: The Last Titan; Shipping Books Press: Drayton, UK, 1996.

16. Thoctarides, K.; Bilalis, A. Shipwrecks of the Greek Seas, Dive into Their History; Aikaterini Laskaridis Foundation: Peraias, Greece, 2015.

17. Mentogiannes, B. 52 Days 1943-The Queen Olga and the Battle of Leros: Underwater Filming and Research; Kastaniotes: Athens, Greece, 2004.

18. Zaloga, S.J. Operation Dragoon 1944, France's Other D-Day; Osprey Publishing Ltd.: Oxford, UK, 2009.

19. Ben-Tzur, Y. The Commander Yehuda Ben-Tzur Palyam \& Aliya Bet Website. Available online: http: //www.palyam.org/English/Hahapala/Teur_haflagot/Rafiah_en (accessed on 2 February 2019).

20. Browne, K. "Ghost Battleships" of the Pacific: Metal Pirates, WWII Heritage, and Environmental Protection. J. Marit. Archaeol. 2018. [CrossRef]

21. Panakera, C. World War II and Tourism Development in Solomon Islands. In Battlefield Tourism; Elsevier: Amsterdam, The Netherlands, 2007; pp. 125-141.

22. Turnbull, G. Remembering D-Day: Revealing the Hidden Wrecks under Normandy Waters. Available online: https://www.naval-technology.com/features/featureremembering-d-day-revealing-the-hiddenwrecks-under-normandy-waters-4143012/ (accessed on 1 February 2019).

23. Browne, K.V. Trafficking in Pacific World War II Sunken Vessels the "Ghost Fleet" of Chuuk Lagoon, Micronesia. J. Law Soc. Sci. 2014. [CrossRef]

24. UNESCO. Safeguarding Underwater Cultural Heritage in the Pacific, Report on the Good Practice in the Protection and Management of World War II-Related Underwater Cultural Heritage; UNESCO: Paris, France, 2017.

25. Timmermans, D.; Guerin, U.; da Silva, A.R. (Eds.) Heritage for Peace and Reconciliation, Safeguarding the Underwater Cultural Heritage of the First World War; UNESCO: Paris, France, 2015.

26. Halpern, P.G. A Naval History of World War I; United States Naval Institute: Annapolis, MD, USA, 1994.

27. Verlinden, V. The Demise of SMS SzentIstván. X-Ray Mag. 2018, 7-8. Available online: https://xray-mag. com/content/demise-sms-szent-istv\%C3\%A1n (accessed on 1 February 2019). 
28. Cibecchini, F.; Hulot, O. The Danton and U-95: Two Symbolic Wrecks to Illustrate and Promote the Heritage of the First World War. In Proceedings of the Scientific Conference on the Occasion of the Centenary of World War I, Bruges, Belgium, 26-27 June 2014; Guérin, U., da Silva, A.R., Simonds, L., Eds.; UNESCO: Paris, France, 2015; pp. 192-198.

29. Kelkit, A.; Celik, S.; Eşbah, H. Ecotourism Potential of Gallipoli Peninsula Historical National Park. J. Coast. Res. 2010, 263, 562-568. [CrossRef]

30. Thys-Şenocak, L. Divided Spaces, Contested Pasts: The Heritage of the Gallipoli Peninsula; Routledge: New York, NY, USA, 2019.

31. Selcuk, K.; Taktak, O.; Karakas, S.; Atabay, M. Echoes from the Deep-Wrecks of the Dardanelles Campaign Gallipoli (Military History); VehbiKoc Foundation: Istanbul, Turkey; Ayhan Sahenk Foundation: Istanbul, Turkey, 2013.

32. MacLeod, I. Corrosion and Conservation Management of the Submarine HMAS AE2 (1915) in the Sea of Marmara, Turkey. Heritage 2019, 2, 868-883. [CrossRef]

33. Veronico, N.A. Hidden Warships, Finding World War II's Abandoned, Sunk, and Preserved Warships, 1st ed.; Zentih Press: Minneapolis, MN, USA, 2015.

34. Dounis, C. Shipwrecks in the Greek Seas; 1900-1950 (Volume A); Finatec: Athens, Greece, 2000. (In Greek)

35. WWII Shipwrecks in the Greek Seas. Available online: http://labtop.topo.auth.gr/wreckhistory/ww2witgs/ (accessed on 7 May 2019).

36. Delaney, D.E. Churchill and the Mediterranean Strategy: December 1941 to January 1943. Def. Stud. 2002, 2, 1-26. [CrossRef]

37. Chant, C. The Encyclopedia of Codenames of World War II (Routledge Revivals); Routledge: New York, NY, USA, 2013.

38. World War II Shipwrecks. GEBCO, IHO-IOC GEBCO, NGS, DeLorme, Esri. Available online: https: //www.arcgis.com/home/webmap/viewer.html?webmap=14b4d42b21f64a2bb69fa1d2389fabdf (accessed on 9 January 2019).

39. Geraga, M.; Katsou, E.; Christodoulou, D.; Iatrou, M.; Kordella, S.; Papatheodorou, G.; Mentogiannis, V.; Kouvas, K. Mapping Natural and Cultural Marine Heritage in Leros Island Greece. In Rapport du 40e Congres de la CIESM 40th; Ciesm, D.E.L.A., Ed.; CIESM: Marseille, France, 2013; Volume 40, p. 847.

40. United Nations Treaty Series. United Nations Convention on the Law of the Sea; United Nations: New York, NY, USA, 1982; pp. 397-576.

41. Council of Europe. Chart of Signatures and Ratification of Treaty 143. In European Convention on the Protection of the Archaeological Heritage (Revised); Council of Europe: Strasbourg, France, 1992; pp. 1-8.

42. ICOMOS. Charter on the Protection and Management of Underwater Cultural Heritage (1996); ICOMOS: Paris, France, 1996.

43. ICOMOS. ICOMOS Charter for the Protection and Management of the Archaeological Heritage (1990); ICOMOS: Paris, France, 1990.

44. Strati, A. Protection of the Underwater Cultural Heritage: From the Shortcomings of the UN Convention. In Unresolved Issues and New Challenges to the Law of the Sea Time before and Time after; Strati, A., Gavouneli, M., Kourtos, N., Eds.; Martinus Nijhoff Publishers: Leiden, The Netherlands, 2006.

45. Ehler, C.; Douvere, F. Marine Spatial Planning: A Step-by-Step Approach, IOC Manuals and Guides 53; UNESCO: Paris, France, 2009.

46. Papageorgiou, M. Aspects of Spatial Planning and Governance in Marine Environments. In Proceedings of the 15th International Conference on Environmental Science and Technology, Organized by Global Network on Environmental Science and Technology, Rhodes, Greece, 31 August-2 September 2017.

47. Strati, A. The Protection of the Underwater Cultural Heritage: An Emerging Objective of the Contemporary Law of the Sea; Martinus Nijhoff Publishers: The Hague, The Netherlands, 1995.

48. Forrest, C. Culturally and Environmentally Sensitive Sunken Warships. Aust. N. Z. Marit. Law J. 2012, 26, $80-88$.

49. Alcaro, L.; Amato, E.; Cabioch, F.; Farchi, C.; Gouriou, V. DEEPP Project Development of European Guidelines for Potentially Polluting Shipwrecks. Deep Proj. 2007. Available online: http://ec.europa.eu/echo/files/civil_ protection/civil/marin/pdfdocs/deepppilotproject.pdf (accessed on 1 February 2019). 
50. Russell, M.A.; Murphy, L.E. USS Arizona Memorial; Dept. of Defense Legacy Resources Management Fund, and National Park Service System wide Archaeological Inventory Program, and USS Arizona Memorial: Sante Fe, NM, USA, 2003.

51. MacLeod, I.D. In-Situ Corrosion Studies on Wrecked Aircraft of the Imperial Japanese Navy in Chuuk Lagoon, Federated States of Micronesia. Int. J. Naut. Archaeol. 2006, 35, 128-136. [CrossRef]

52. Giannakopoulos, C.; Bindi, M.; Le Sager, P.; Goodess, C.M.; Moriondo, M.; Kostopoulou, E. Climatic Changes and Associated Impacts in the Mediterranean Resulting from a $2{ }^{\circ} \mathrm{C}$ Global Warming. Glob. Planet. Change. 2009, 68, 209-224. [CrossRef]

53. Gregory, D.J. Development of Tools and Techniques to Survey, Assess, Stabilise, Monitor and Preserve Underwater Archaeological Sites: SASMAP. Int. Arch. Photogramm. Remote Sens. Spat. Inf. Sci. 2015, XL-5/W7, 173-177. [CrossRef]

54. Elfadaly, A.; Lasaponara, R.; Murgante, B.; Qelichi, M.M. Cultural Heritage Management Using Analysis of Satellite Images and Advanced GIS Techniques at East Luxor, Egypt and Kangavar, Iran (A Comparison Case Study). In Lecture Notes in Computer Science (Including Subseries Lecture Notes in Artificial Intelligence and Lecture Notes in Bioinformatics); Springer: Cham, Switzerland, 2017; pp. 152-168.

55. Bruno, F.; Lagudi, A.; Ritacco, G.; Agrafiotis, P.; Skarlatos, D.; Cejka, J.; Kouril, P.; Liarokapis, F.; Philpin-Briscoe, O.; Poullis, C.; et al. Development and Integration of Digital Technologies Addressed to Raise Awareness and Access to European Underwater Cultural Heritage. An Overview of the H2020 i-MARECULTURE Project. In OCEANS 2017-Aberdeen; IEEE: Piscataway, NJ, USA, 2017; pp. 1-10.

56. Olejnik, C. Visual Identification of Underwater Objects Using a ROV-Type Vehicle: "Graf Zeppelin" Wreck Investigation. Pol. Marit. Res. 2008, 15, 72-79. [CrossRef]

57. Haugan, I. Using New Technology to Find Shipwrecks on the Ocean Floor; Gemini Research News: Trondheim, Norway, 2018.

58. Bruno, F.; Lagudi, A.; Barbieri, L.; Muzzupappa, M.; Ritacco, G.; Cozza, A.; Cozza, M.; Peluso, R.; Lupia, M.; Cario, G. Virtual and Augmented Reality Tools to Improve the Exploitation of Underwater Archaeological Sites by Diver and Non-Diver Tourists. In Digital Heritage-Progress in Cultural Heritage: Documentation, Preservation, and Protection, 6th International Conference, EuroMed 2016; Ioannides, M., Fink, E., Moropoulou, A., Hagedorn, M., Fresa, A., Liestol, G., Rajcic, V., Grussenmeyer, P., Eds.; Springer International Publishing: Nicosia, Cyprus, 2016; pp. 269-280.

59. MARE CULTURE Project. Advanced VR, iMmersive Serious Games and Augmented REality as Tools to Raise Awareness and Access to European Underwater CULTURal Heritage. Available online: https: //imareculture.eu/ (accessed on 2 February 2019).

60. Firth, A. Marine Spatial Planning and the Historic Environment; Fjordr: Salisbury, UK, 2013.

61. EMODnet. Data on Bathymetry (Water Depth), Coastlines, and Geographical Location of Underwater Features: Wrecks. Available online: http://portal.emodnet-bathymetry.eu/ (accessed on 2 February 2019).

62. Monfils, R. The Global Risk of Marine Pollution from WWII Shipwrecks: Examples from the Seven Seas. In International Oil Spill Conference Proceedings; American Petroleum Institute: Washington, DC, USA, 2005; Volume 2005, pp. 1049-1054.

63. Lickliter-Mundon, M.; Cantelas, F.; Coble, W.; Kinney, J.; McKinnon, J.; Meyer, J.; Pietruszka, A.; Pilgrim, B.; Pruitt, J.R.; Van Tilburg, H. Identification of a Deep-Water B-29 WWII Aircraft via ROV Telepresence Survey. J. Marit. Archaeol. 2018, 13, 167-189. [CrossRef]

64. Argyropoulos, V.; Giannoulaki, M.; Charalambous, D. (Eds.) Conservation of Underwater Metallic Shipwrecks and Their Finds from the Aegean (in Greek); Dionicos: Athens, Greece, 2015.

65. Van Tilberg, H. Second World War Underwater Cultural Heritage Issues in Hawaii. In Safeguarding Underwater Cultural Heritage in the Pacific; PUCHP, Ed.; UNESCO: Paris, France, 2017; pp. 43-52.

66. Jeffery, B. Submerged Second World War Sites in Chuuk, Guam, Pohnepei and Yap. In Safeguarding Underwater Cultural Heritage in the Pacific; PUCHP, Ed.; UNESCO: Paris, France, 2017; pp. 53-71.

67. McKinnon, J. Second World War Underwater Cultural Heritage Management in Saipan. In Safeguarding Underwater Cultural Heritage in the Pacific; PUCHP, Ed.; UNESCO: Paris, France, 2017; pp. 31-42.

68. Kimura, J. Interpreting Maritime Cultural Space through the Utilization of GIS: A Case Study of the Spatial Meaning of Shipwrecks in the Coastal Waters of South Australia. Master's Thesis, Flinders University, Adelaide, Australia, 2006. 
69. Nairn, A.D. The Development of an Australian Marine Spatial Information System (AMSIS) to Support Australian Government Ocean Policy and Multi-Use Marine Activities. In Coastal and Marine Geospatial Technologies; Green, D.R., Ed.; Coastal Systems and Continental Margins; Springer: Dordrecht, The Netherlands, 2010; Volume 13, pp. 17-27.

70. UNESCO. The Side Event on Safeguarding Underwater Cultural Heritage (UCH) for Sustainable Development Took Place on 1 November 2018 at the Inter-Regional Meeting for the Mid-Term Review of the SAMOA Pathway (Apia, 30 October-1 November 2018). Available online: http://www.unesco.org/new/pt/culture/themes/underwater-cultural-heritage/dynamic-content-singleview/news/safeguarding_underwater_cultural_heritage_for_blue_economy-1/ (accessed on 2 February 2019).

71. Said, S.Y.; Zainal, S.S.; Thomas, M.G.; Goodey, B. Sustaining Old Historic Cities through Heritage-Led Regeneration. WIT Trans. Ecol. Environ. 2013, 179, 267-278. [CrossRef]

72. Alvarez, M.D.; Go, F.M.; Yuksel, A. (Eds.) Heritage Tourism Destinations: Preservation, Communication and Development; CAB International: Boston, MA, USA, 2016.

73. European Commission. Towards an Integrated Approach to Cultural Heritage for Europe; European Commission: Brussels, Belgium, 2014.

74. European Commission. Communication from the Commission to the Council and the European Parliament-Thematic Strategy on the Protection and Conservation of the Marine Environment; European Commission: Brussels, Belgium, 2005.

75. European Commission. A European Strategy for More Growth and Jobs in Coastal and Maritime Tourism; European Commission: Brussels, Belgium, 2014.

76. Michel, J.; Gilbert, T.; Etkin, D.S.; Urban, R.; Waldron, J.; Blocksidge, C.T. An Issue Paper Prepared for the 2005 International Oil Spill Conference: Potentially Polluting Wrecks in Marine Waters. In International Oil Spill Conference Proceedings; American Petroleum Institute: Washington, DC, USA, 2005; Volume 2005, pp. 1-40.

77. Landquist, H.; Hassellöv, I.-M.; Rosén, L.; Lindgren, J.F.; Dahllöf, I. Evaluating the Needs of Risk Assessment Methods of Potentially Polluting Shipwrecks. J. Environ. Manag. 2013, 119, 85-92. [CrossRef]

78. Spira, J. Wrecks and Reefs! Spira International Inc.: Huntington Beach, CA, USA, 2004.

79. Genç, T.S.; Özgül, A.; Lök, A. The Use of Artificial Reefs for Recreational Diving. Turk. J. Marit. Mar. Sci. 2017, 3, 27-33.

80. Stratigea, A.; Katsoni, V. A Strategic Policy Scenario Analysis Framework for the Sustainable Tourist Development of Peripheral Small Island Areas-The Case of Lefkada-Greece Island. Eur. J. Futures Res. 2015, 3, 5. [CrossRef]

81. European Commission. Blue Growth Opportunities for Marine and Maritime Sustainable Growth; European Commission: Brussels, Belgium, 2012.

82. European Commission. Commission Staff Working Document Report on the Blue Growth Strategy towards More Sustainable Growth and Jobs in the Blue Economy; European Commission: Brussels, Belgium, 2017.

83. Panagiotopoulou, M.; Somarakis, G.; Stratigea, A. Smartening Up Participatory Cultural Tourism Planning in Historical City Centers. J. Urban Technol. 2018, 1-24. [CrossRef]

84. List, R.A.; Hadeed, M.; Goldzweig, R.S.; Cohen, J.L. Online Participation in Culture and Politics: Towards More Democratic Societies? Council of Europe: Brussels, Belgium, 2018.

85. Hannahs, T. Underwater Parks Versus Preserves: Data or Access; Springer: Boston, MA, USA, 2003; pp. 5-16. [CrossRef]

86. Scott-Ireton, D.A. The Value of Public Education and Interpretation in Submerged Cultural Resource Management. In Out of the Blue; Springer: Boston, MA, USA, 2007; pp. 19-32.

87. Altvater, S. How to Integrate Maritime Cultural Heritage into Maritime Spatial Planning? Available online: https://www.submariner-network.eu/images/events/betteroffblue17/5_wsC_SAltvaterilovepdf-compressed.pdf (accessed on 10 February 2019).

88. Balint, P.J.; Stewart, R.E.; Desa, A.; Walters, L.C. Wicked Environmental Problems Managing Uncertainty and Conflict; Island Press: Washington, DC, USA, 2011.

89. Boyd, B.; Cotter, M.; O'Connor, W.; Sattler, D. Cognitive Ownership of Cultural Places: Social Construction and Cultural Heritage Management. Tempus 1996, 6, 123-140.

90. Kisić, V. Governing Heritage Dissonance-Promises and Realities of Selected Cultural Policies; European Cultural Foundation: Belgrade, Serbia, 2013. 
91. Papuccular, H. Fragmented Memories the Dodecanese Islands during WWII. In Heritage and Memory of War Responses from Small Islands; Gilly, C., Keir, R., Eds.; Routledge: Abingdon, UK, 2015, 2015.

92. Jordi, P.B.; Čopič, V.; Srakar, A. Literature Review on Cultural Governance and Cities. Kult-ur 2014, 1, $183-200$. [CrossRef]

93. The Council of the European Union. Council Conclusions on Participatory Governance of Cultural Heritage; The Council of the European Union: Brussels, Belgium, 2014; pp. 22-24.

94. Dromgoole, S. The Evolution of International Law on Underwater Cultural Heritage. In Underwater Cultural Heritage and International Law; Cambridge University Press: Cambridge, UK, 2013; pp. 28-64.

95. Jameson, J.H. Not All Wet: Public Presentation, Stewardship, and Interpretation of Terrestrial vs. Underwater Sites. In Out of the Blue; Springer: Boston, MA, USA, 2007; pp. 7-18.

96. Fredheim, L.H.; Khalaf, M. The Significance of Values: Heritage Value Typologies Re-Examined. Int. J. Herit. Stud. 2016, 22, 466-481. [CrossRef]

97. Pye, E. Caring for the Past: Issues in Conservation for Archaeology and Museums; James \& James: London, UK, 2001.

98. Van Vliet, W. The Future of Relics from a Military Past; University of Groningen: Groningen, The Netherlands, 2016.

99. Fatorić, S.; Seekamp, E. A Measurement Framework to Increase Transparency in Historic Preservation Decision-Making under Changing Climate Conditions. J. Cult. Herit. 2018, 30, 168-179. [CrossRef]

100. Shearing, S. Here Today, Gone Tomorrow? Climate Change and World Heritage; Macquarie Law Working Paper Series; Macquarie University: Sydney, Australia, 2007.

101. Perez-Alvaro, E. Climate Change and Underwater Cultural Heritage: Impacts and Challenges. J. Cult. Herit. 2016, 21, 842-848. [CrossRef]

102. EEA. The European Environment—State and Outlook; EEA: Luxembourg, 2015.

103. Panagou, N.; Kokkali, A.; Stratigea, A. Towards an Integrated Participatory Marine/Coastal and Territorial Spatial Planning Approach at the Local Level-Planning Tools and Issues Raised. Reg. Sci. Inq. 2018, 10, 87-111.

104. CBI. CBI Product Factsheet: Dive Tourism from Europe; CBI: The Hague, The Netherlands, 2015.

105. PADI. PADI 2019 Worldwide Corporate Statistics, Data for 2013-2018; PADI: Rancho Santa Margarita, CA, USA, 2019.

106. Poon, A. Tourism, Technology and Competitive Strategies; CAB International: Oxon, UK, 1993.

107. Lazaretou, S. Smart Economy - Cultural and Creative Industry in Greece: Can They Support a Way Out from Recession Period? (in Greek), Working Papers 175, Bank of Greece Report. 2014, pp. 73-704. Available online: http://www.bankofgreece.gr/BogEkdoseis/Paper2014175.pdf (accessed on 1 February 2019).

108. Papageorgiou, M.; Kyvelou, S. Aspects of Marine Spatial Planning and Governance: Adapting to the Transboundary Nature and the Special Conditions of the Sea. Eur. J. Environ. Sci. 2018, 8, 31-37. [CrossRef]

109. Dissonant Heritage. Available online: https://dissonantheritage.wordpress.com/ (accessed on 28 May 2019).

110. Cobb, E. Cultural Heritage in Conflict: World Heritage Cities of the Middle East. Master's Thesis, University of Pennsylvania, Philadelphia, PA, USA, 2010.

111. Trindade Lopes, M.H.; Almeida, I.C.G. The Mediterranean: The Asian and African Roots of the Cradle of Civilization. In Mediterranean Identities_Environment, Society, Culture; Fuerst-Bjelis, B., Ed.; InTech: Croacia, 2017.

(C) 2019 by the authors. Licensee MDPI, Basel, Switzerland. This article is an open access article distributed under the terms and conditions of the Creative Commons Attribution (CC BY) license (http://creativecommons.org/licenses/by/4.0/). 